\title{
A Distribution-Free Description of Fragmentation by Blasting Based on Dimensional Analysis
}

\author{
José A. Sanchidrián ${ }^{1}$ (1) $\cdot$ Finn Ouchterlony ${ }^{2}$
}

Received: 14 April 2016/Accepted: 9 November 2016/Published online: 28 November 2016

(C) The Author(s) 2016. This article is published with open access at Springerlink.com

\begin{abstract}
A model for fragmentation in bench blasting is developed from dimensional analysis adapted from asteroid collision theory, to which two factors have been added: one describing the discontinuities spacing and orientation and another the delay between successive contiguous shots. The formulae are calibrated by nonlinear fits to 169 bench blasts in different sites and rock types, bench geometries and delay times, for which the blast design data and the size distributions of the muckpile obtained by sieving were available. Percentile sizes of the fragments distribution are obtained as the product of a rock mass structural factor, a rock strength-to-explosive energy ratio, a bench shape factor, a scale factor or characteristic size and a function of the in-row delay. The rock structure is described by means of the joints' mean spacing and orientation with respect to the free face. The strength property chosen is the strain energy at rupture that, together with the explosive energy density, forms a combined rock strength/explosive energy factor. The model is applicable from 5 to 100 percentile sizes, with all parameters determined from the fits significant to a 0.05 level. The expected error of the prediction is below $25 \%$ at any percentile. These errors are half to onethird of the errors expected with the best prediction models available to date.
\end{abstract}

Keywords Rock blasting - Fragmentation prediction - Size distribution - Dimensional analysis $\cdot$ Kuz-Ram $\cdot$ Swebrec

José A. Sanchidrián

ja.sanchidrian@upm.es

1 ETSI Minas y Energía, Universidad Politécnica de Madrid, Madrid, Spain

2 Department of Mineral Resources Engineering, Montanuniversitaet Leoben, Leoben, Austria

\section{Introduction}

The main goal of rock blasting is the fragmentation of the rock mass. Prediction of the size distribution of the fragmented rock from the rock mass characteristics, the blast design parameters (both in terms of the geometry and of the initiation sequence) and the explosive properties is a challenge that has been undertaken for decades, and is currently available to the blasting engineer in the form of formulae that relate the parameters of a given size distribution function to the rock properties and the blast design parameters.

One of the most relevant fragmentation by blasting formulae is the Kuznetsov (1973) one:

$x_{m}=A q^{-0.8} Q^{1 / 6}$

where $x_{m}$ is the mean fragment size in $\mathrm{cm}, A$ is a rock strength factor in the range 7-13, $q$ is the powder factor (or specific charge, or charge concentration-explosive mass per unit rock volume) in $\mathrm{kg} / \mathrm{m}^{3}$ and $Q$ is the charge per hole in $\mathrm{kg}$. These three factors comply essentially with the expected behavior of rock fragmentation by blasting. Essentially, the Kuznetsov formula means that (1) the harder the rock, the bigger the fragments; (2) the higher the specific amount (powder factor) of explosive, the smaller the fragments; and (3) the larger the scale (the charge per hole is used as scale factor, and larger charges per hole indicate larger drill patterns), the larger the fragments. In Eq. 1, the amounts of explosive in the powder factor and the charge per hole are given in TNT equivalent mass. Such equivalent mass can be calculated multiplying the mass of explosive by its relative strength with respect to TNT; if such strength is $\theta$, Eq. 1 can be written as (Kuznetsov 1973, Eq. 12): 
Table 1 Blast and fragmentation data: blast sites, rock types and references

\begin{tabular}{|c|c|c|}
\hline Blast site & Rock & References \\
\hline El Alto quarry, Spain & Limestone & Segarra and Sanchidrián (2003), Sanchidrián et al. (2006) \\
\hline Mt. Coot-tha quarry, Australia & Hornfels & Kojovic et al. (1995), LeJuge and Cox (1995) \\
\hline Bårarp quarry, Sweden & Granitic gneiss & Olsson and Bergqvist (2002), Moser et al. (2003) \\
\hline Kållered quarry, Sweden & Gneissic granite & Gynnemo (1997) \\
\hline Billingsryd quarry, Sweden & Dolerite & Gynnemo (1997) \\
\hline Rolla quarry, MO, USA & Dolomite & Otterness et al. (1991) \\
\hline High Forest quarry, MN, USA & $\begin{array}{l}\text { Dolomitic } \\
\text { limestone }\end{array}$ & Ash (1973), Dick et al. (1973) \\
\hline $\begin{array}{l}\text { Guan Shan copper mine, Jiang Shu, } \\
\text { China }\end{array}$ & Rhyoporphyry & Ma et al. (1983) \\
\hline Rolla quarry, MO, USA & Dolomite & Stagg and Nutting (1987) \\
\hline Waterloo quarry, IA, USA & Limestone & Stagg et al. (1989) \\
\hline St Paul Park quarry, MN, USA & Dolomite & Stagg and Rholl (1987) \\
\hline Granite Falls quarry, MN, USA & Granitic gneiss & Stagg and Otterness (1995) \\
\hline Manitowoc quarry, WI, USA & Dolomite & Stagg and Otterness (1995) \\
\hline Vändle quarry, Sweden & Granite & $\begin{array}{l}\text { Ouchterlony et al. (2005, 2006), Ouchterlony and Moser (2006), Liu et al. } \\
\text { (2011) }\end{array}$ \\
\hline Långåsen quarry, Sweden & Granodiorite & Ouchterlony et al. $(2010,2015)$ \\
\hline Rolla quarry, MO, USA & Dolomite & Smith (1976) \\
\hline Rolla quarry, MO, USA & Dolomite & Brinkmann (1982) \\
\hline Rolla quarry, MO, USA & Dolomite & Bleakney (1984) \\
\hline
\end{tabular}

$x_{m}=A q^{-0.8} Q^{1 / 6} \theta^{-19 / 30}$

in which $q$ and $Q$ refer to actual mass of explosive of relative strength $\theta$. Equation 1 or its equivalent Eq. 2 is written originally for the mean size $x_{m}$ of a Rosin-Rammler (RR) distribution (Rosin and Rammler 1933; Weibull 1939, 1951) that was assumed to accurately describe the fragmented rock. The Rosin-Rammler, or Weibull, cumulative distribution function is:

$P(x)=1-\exp \left[-\left(\frac{x}{x_{\mathrm{c}}}\right)^{n}\right]=1-\exp \left[-\ln 2\left(\frac{x}{x_{50}}\right)^{n}\right]$

where $x_{\mathrm{c}}$ is the characteristic size (the size for which the passing fraction is $1-1 / e$, or $63.2 \%$ ) and $n$ is a shape factor, usually quoted as uniformity index; the expression on the right is written with the median size $x_{50}$ instead of $x_{\mathrm{c}}$. The use of the RR distribution for rock fragmented by blasting had been positively assessed by Baron and Sirotyuk (1967) and Koshelev et al. (1971), which is used by Kuznetsov (1973).

The Soviet literature of the time does not make it entirely clear whether Eqs. 1 or 2 refer to the mean or the characteristic size (which value is close to the mean if the shape index of the distribution is not much different than one). There has been some controversy (Spathis
2004, 2009, 2012, 2016; Ouchterlony 2016a, b) about the actual size that the Kuznetsov formula was addressing. For all practical purposes, it has been calibrated, tailored and used over the years to estimate the median size $x_{50}$ (Cunningham 1987, 2005; Rollins and Wang 1990; Raina et al. 2002, 2009; Liu 2006; Cáceres Saavedra et al. 2006; Borquez 2006; Rodger and Gricius 2006; Vanbrabant and Espinosa Escobar 2006; Mitrovic et al. 2009; Engin 2009; Gheibie et al. 2009a, b; Bekkers 2009; McKenzie 2012; Sellers et al. 2012; Faramarzi et al. 2015; Jahani and Taji 2015; Singh et al. 2015; Adebola et al. 2016).

Kuznetsov derived his formula based on blasting tests in limestone specimens reported by Koshelev et al. (1971). These consisted of eleven small- to mid-scale shots in irregular limestone blocks, with RDX charges of 0.5-500 g. Kuznetsov then assessed the formula with some data from large-scale tests by Marchenko (1965), 6 blasts in limestone, 6 blasts in a medium-hard rock and 14 blasts in hard and very hard rock (the exact rock type is not reported, nor is the explosive used). A values recommended by Kuznetsov were 7, 10 and 13 for medium-to-hard, hard fissured and hard massive rocks, respectively. Kuznetsov mentions that the mean deviation of experimental data from the theoretical (i.e., predicted) data is $\pm 15 \%$; a detailed analysis of the data and the predictions by Eqs. 1 or 2 gives a mean error of $9 \%$, with minimum and 
maximum errors of -42 and $55 \%$, respectively (Ouchterlony 2016a). This matter will be re-assessed in this work.

About ten years after its publication, the Kuznetsov formula was popularized by Cunningham (1983), who wrote it so as to use the relative weight strength with respect to ANFO, the standard explosive in civil applications, instead of TNT, in what became the popular KuzRam model. In his text, Cunningham uses the term 'mean fragment size,' but his mathematical definition of it implies the median; he in fact uses the symbol $x_{50}$. In the Kuz-Ram papers that followed (Cunningham 1987, 2005), the term mean is also used but again contradicted by figures and equations that imply $x_{50}$ :

$x_{50}=A q^{-0.8} Q^{1 / 6}\left(\frac{\mathrm{RWS}}{115}\right)^{-19 / 30}$

Here RWS is the relative weight strength (heat of explosion, or energy in general, ratio with respect to ANFO, in percent; 115 is the relative weight strength of TNT). Cunningham (1987) adapted a blastability index proposed by Lilly (1986) to replace Kuznetsov's numerical rock factor:

$A=0.06 \cdot(\mathrm{RMD}+\mathrm{JF}+\mathrm{RDI}+\mathrm{HF})$

The form of the rock mass description term (RMD) has had some changes over the years; in its final form (Cunningham 2005), it is:

$\mathrm{RMD}=10$ (powdery/friable), JF (if vertical joints) or 50 (massive);

JF (joint factor) = JPS (joint plane spacing) + JPA (joint plane angle);

JPS $=10 \quad$ (average $\quad$ joint $\quad$ spacing $\left.S_{J}<0.1 \mathrm{~m}\right), 20$ $\left(0.1 \leq S_{J}<0.3 \mathrm{~m}\right), \quad 80 \quad\left(0.3 \mathrm{~m} \leq S_{J}<0.95 \cdot(B \cdot S)^{1 / 2}\right.$, $B$ and $S$ being burden and spacing), $50\left(S_{J}>(B \cdot S)^{1 / 2}\right)$. Cunningham (2005) incorporates a joint condition correction factor that multiplies the joint plane spacing, with value $1,1.5$ and 2 for tight, relaxed and gouge-filled joints, respectively;

JPA $=20$ (dip out of face), 30 (strike perpendicular to face) or 40 (dip into face). Cunningham does not give a JPA value for horizontal planes but Lilly (1986) assigns them JPA $=10$.

The rock density influence (RDI) is:

$\mathrm{RDI}=0.025 \cdot \rho-50$.

$\rho$ being density $\left(\mathrm{kg} / \mathrm{m}^{3}\right)$. Finally, the hardness factor (HF) is:

$$
\begin{aligned}
& \mathrm{HF}=E / 3 \text { if } E<50, \text { or } \\
& \mathrm{HF}=\sigma_{\mathrm{c}} / 5 \text { if } E>50 .
\end{aligned}
$$

$\sigma_{\mathrm{c}}$ and $E$ being uniaxial compressive strength (MPa) and Young's modulus (GPa).
The form of RMD implies that JF may enter twice in Eq. 5, directly and through RMD. The direct term in Eq. 5 Cunningham (1987) is in all probability a printing error and Cunningham (2005) removed it in later Kuz-Ram model updates, so that:

$A=0.06 \cdot(\mathrm{RMD}+\mathrm{RDI}+\mathrm{HF})$

Cunningham (2005) also incorporated a delay-dependent factor in the central size formula, based on Bergmann et al. (1974) data:

$$
\begin{aligned}
A_{t} & =0.66\left(\frac{\Delta T}{T_{\max }}\right)^{3}-0.13\left(\frac{\Delta T}{T_{\max }}\right)^{2}-1.58\left(\frac{\Delta T}{T_{\max }}\right)+2.1 \\
& \times \frac{\Delta T}{T_{\max }}<1 \\
A_{t} & =0.9+0.1\left(\frac{\Delta T}{T_{\max }}-1\right), \quad \frac{\Delta T}{T_{\max }}>1
\end{aligned}
$$

where $T_{\max }=15.6 B / c_{P} ; \Delta T$ is in-row delay (ms), $B$ is burden $(\mathrm{m})$ and $c_{P}$ is $P$-wave velocity $(\mathrm{m} / \mathrm{ms})$. Note that $A_{t}$ is not continuous at $\Delta T / T_{\max }=1$, but replacing the constant term 2.1 by 2.05 would make it so.

As previously stated, the various factors (e.g., the rock description pre-factor 0.06) were tailored by Cunningham to fit the median. The final form of the Kuznetsov-Cunningham formula should be (Cunningham 2005):

$x_{50}=A A_{t} q^{-0.8} Q^{1 / 6}\left(\frac{\mathrm{RWS}}{115}\right)^{-19 / 30} C(A)$

The factor $C(A)$ is included in order to correct the predicted median size, to be determined experimentally from data in a given site; according to Cunningham, it would normally be within the range $0.5<C(A)<2.0$. This suggests a prediction error expected of up to about $100 \%$. This is larger than Kuznetsov's (1973) error bounds, but while Kuznetsov's $A$ values lie in the range 7-13, Cunningham (1987) covers the much wider range 0.8-22.

Besides adapting Kuznetsov's central size formula, Cunningham (1983) followed up the conclusion of the Soviet researchers that the fragmented rock could be described by the RR function and formulated an equation for the uniformity or shape index ( $n$ in Eq. 3 ); in its final form, after several corrections and refinements (Cunningham 1987, 2005), the shape index for the RR distribution of rock fragments is:

$n=n_{s}\left(2-0.03 \frac{B}{d}\right)^{0.5}\left(\frac{1+S / B}{2}\right)^{0.5}\left(1-\frac{W}{B}\right)\left(\frac{l_{\mathrm{c}}}{H}\right)^{0.3}\left(\frac{A}{6}\right)^{0.3} C(n)$

where $W$ is drilling deviation, $l_{\mathrm{c}}$ is charge length, $H$ is bench height and $n_{s}$ is a factor that accounts for the delay precision: 
$n_{s}=0.206+\left(1-R_{s} / 4\right)^{0.8}, \quad R_{s}=6 s_{t} / \Delta T$

where $s_{t}$ is the standard deviation of the initiation system. The factor $C(n)$ is, again, a variable correction to match experimental data if available; no expected range is given to it. ${ }^{1}$

The Kuznetsov-Cunningham formula is physically sound, as previously discussed. Similar forms may be obtained applying asteroid collision principles (Holsapple and Schmidt 1987; Housen and Holsapple 1990) as shown by Ouchterlony (2009b). However, the experimental data supporting the median size expression are, as mentioned above, extremely limited. Furthermore, no experimental data supporting the shape index formula seem to have been reported. The initial shape index dependence on geometry appears to originate in 2D blast modeling by Lownds (1983) (Cunninghan 1983, p. 441). ${ }^{2}$

The assessment of the Kuz-Ram model by, e.g., the JKMRC (Kanchibotla et al. 1999; Thornton et al. 2001; Brunton et al. 2001) and other publications (e.g., Ford 1997; Morin and Ficarazzo 2006; Gheibie et al. 2009a, b; Hafsaoui and Talhi 2009; Strelec et al. 2011; Tosun et al. 2014) seldom include hard experimental data and are often obscured by the lack of real knowledge of the resulting muckpile fragmentation, which hinders a reliable error assessment. A generally accepted weakness of the Kuz-Ram model is that it normally predicts too few fines in a muck pile. This led to model extensions involving one RR function for the coarse material and another for the fines, the crush zone model (CZM, Kanchibotla et al. 1999; Thornton et al. 2001; Brunton et al. 2001) and the two-component model (TCM, Djordjevic 1999) from the JKMRC. Of these, the CZM has become the one more used. The CZM rests on the assumption that the fines come from a volume around the borehole in which the rock may fail under compression (it is 'crushed'); the radius of the crush zone is:

$r_{\mathrm{c}}=r_{\mathrm{b}} \sqrt{\frac{P_{\mathrm{b}}}{\sigma_{\mathrm{c}}}}$

where $r_{\mathrm{b}}$ is the borehole radius, $P_{\mathrm{b}}$ is the borehole pressure and $\sigma_{\mathrm{c}}$ is the uniaxial compressive strength. The crushed volume is a fraction $F_{\mathrm{c}}$ of the volume excavated by each borehole, BHS:

$F_{\mathrm{c}}=\frac{\pi\left(r_{\mathrm{c}}^{2}-r_{\mathrm{b}}^{2}\right)\left(H-l_{\mathrm{s}}\right)}{\mathrm{BHS}}$

where $l_{\mathrm{s}}$ is the stemming length. The crushed zone

${ }^{1}$ The factor $(A / 6)^{0.3}$ in Eq. 8 is absent in Cunningham (2005), Eq. 14. This must be a typographical error since this factor is defined in his Eq. 12 and present in his Table 1. The factor $(A / 6)^{0.3}$ introduces a weak dependence of $n$ on rock mass conditions.

2 As a strong indicator of the source, we take, e.g., Lownds's Fig. 8. From it follows the term $1-W / B$ in the $n$-factor formula. maximum size of fragments is assumed to be $1 \mathrm{~mm}$. The CZM uses the Kuz-Ram model ${ }^{3}$ for the coarse part (above $50 \%$ passing for competent rock, $\sigma_{\mathrm{c}}>50 \mathrm{MPa}$, and $90 \%$ for soft rock, $\sigma_{\mathrm{c}}<10 \mathrm{MPa}$ ), below which a second RR function is used, defined so as to include (for the competent rock case $)$ the $\left(x_{50}, 0.5\right)$ and $\left(1 \mathrm{~mm}, F_{\mathrm{c}}\right)$ points; for the soft rock case, the grafting point is $\left(x_{90}, 0.9\right) .{ }^{4}$ Such a 'fines' RR function is defined by $x_{50}$ and a uniformity index $n_{f}$ :

$n_{f}=\frac{\ln \left[-\frac{\ln \left(1-F_{c}\right)}{\ln 2}\right]}{\ln \left[1 / x_{50}(\mathrm{~mm})\right]}$

An analogous expression can be obtained for the soft rock case.

Both the Kuz-Ram model and its CZM extension have been assessed with the data set of 169 blasts that is described in Sect. 3. Figure 1 shows the logarithmic errors of the size prediction:

$e_{L}=\ln \left(\frac{x^{*}}{x}\right)$

where $x^{*}$ and $x$ are predicted and data sizes, respectively. ${ }^{5}$

The error of the Kuz-Ram and crush zone predictions in about half of the cases (the interquartile range) lies within an approximate range $[-0.6,0.4]$, roughly equivalent to relative errors -75 to $+50 \%$ in nearly the whole percentage passing range. The prediction is noticeably negativebiased (the sizes predicted are smaller than the data) in most of the range except the upper end. Other conclusions from Fig. 1 are that the largest bias occurs in the central zone, which suggests that (1) the median size formula has a limited predictive capability in terms of accuracy, with a systematic error of some $-30 \%$; the precision (i.e., the random error around the central value) is also limited, with the interquartile range of about $[-75,+50 \%]$; this prediction error is larger than the assessment by Ouchterlony (2016a) on the original Kuznetsov's formula ( -42 to $55 \%$ maximum error), though the number of blasts used in the present case more than quadruples the data set used by Kuznetsov; (2) the prediction in the extremes of the range analyzed is somewhat better than in the central range which

\footnotetext{
${ }^{3}$ In what the CZM makes use of the Kuz-Ram formulae, their last versions (Eqs. 6-10, Cunningham 2005) have been used. The CZM contains an in-house redefinition of the rock factor $A$, which seems to have never been officially published; it is used here in its original form, i.e., Kuz-Ram's rock factor.

${ }^{4}$ Kanchibotla et al. (1999) say that 'It is likely that for intermediate strength rocks the point where the two distributions are joined will vary between $x_{50}$ and $x_{90}$.' How this is effected in practical applications has not been published however.

5 Note that a $\log$ error $\pm \ln 2= \pm 0.69$ means a prediction value double or half the data value, $\pm \ln 3= \pm 1.10$ corresponds to triple/ one-third, etc.
} 
Fig. 1 Boxplots of the prediction error for the KuzRam and crush zone models, based on the data set of 169 blasts. Blue boxes Kuz-Ram; magenta boxes CZM.

Horizontal lines show the $\ln 1.5$ and $-\ln 1.75$ levels, equivalent to relative errors +50 and $-75 \%$ (color figure online)

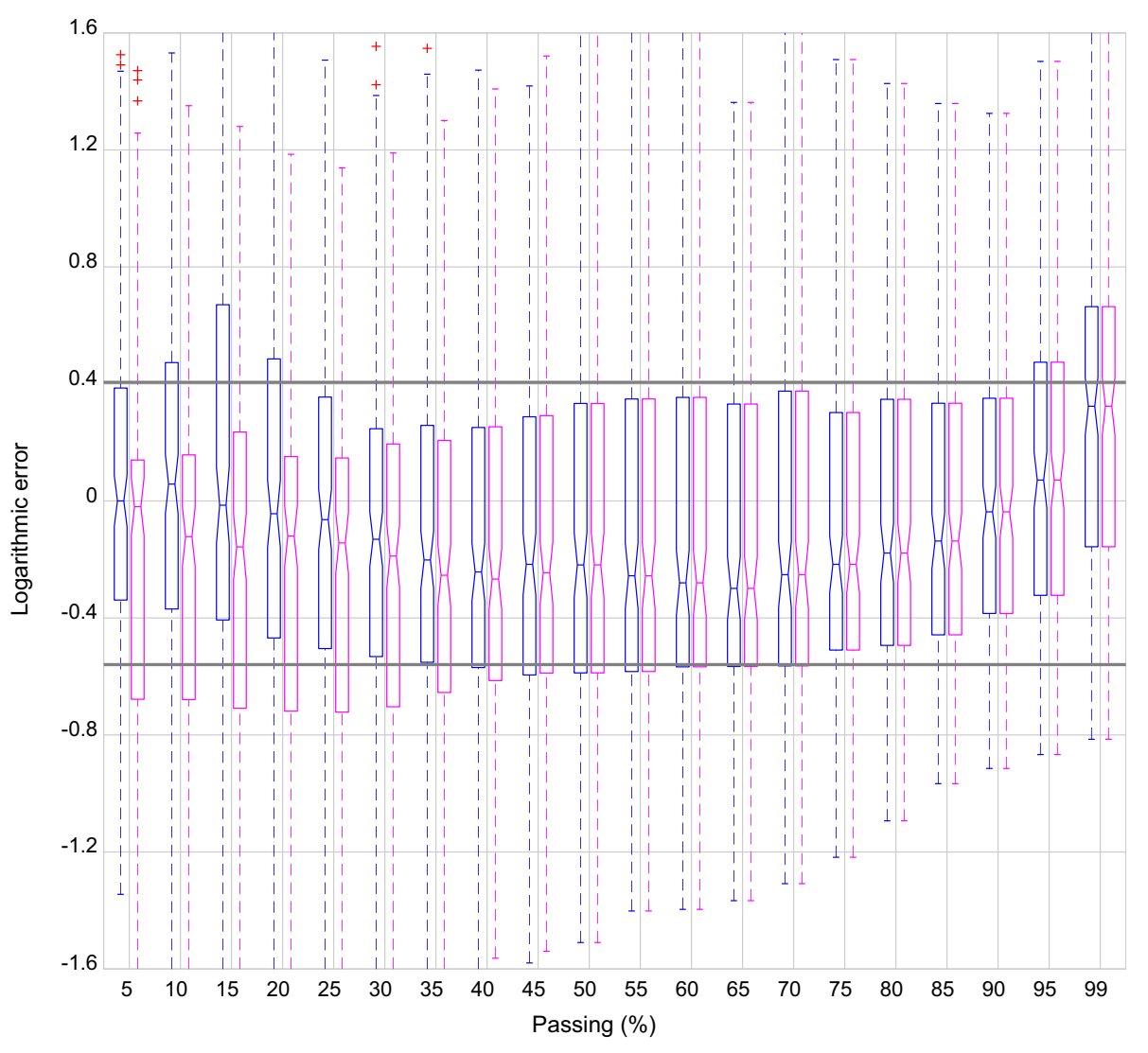

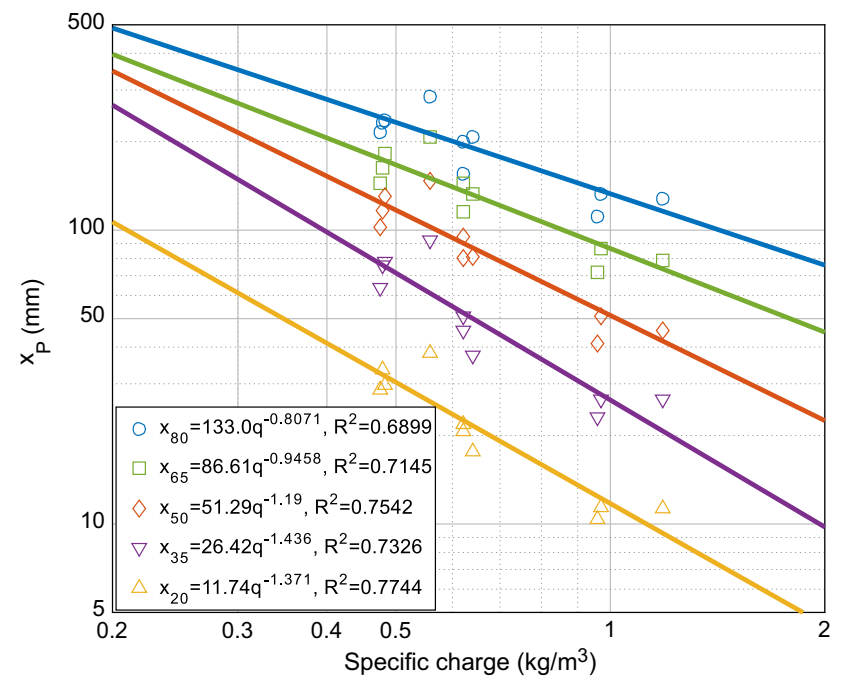

Fig. 2 Log-log interpolated percentile size data $x_{P}$ for rounds \#1, 2, 5, 6, 13, 14, 18, 19, 25, 29 from Otterness et al. (1991) with $P=20$, $35,50,65$ and $80 \%$. Fitted power laws $x_{P}=A / q^{\kappa}$ are plotted (color figure online)

means that also the uniformity (the overall slope in the size/passing plot in $\log -\log$ ) of the distribution is generally overestimated.

The data from the seminal small-scale (bench height of about $1 \mathrm{~m}$ ) blasting tests by Otterness et al. (1991) underscore the above. Plotting some percentile sizes as a function of the powder factor from a selection of 10 blasts of nearly identical geometry gives the results shown in Fig. 2. Power laws fit each percentile size quite well (the determination coefficients are given in the figure; both the pre-factor and the exponent are significant in all the fits, and the maximum $p$ values are 0.002 for the pre-factor and 0.003 for the exponent). Ouchterlony et al. (2016) show that such pattern requires that (1) the RR exponent would need to be variable at different percentiles (which would require a different function-e.g., a piecewise RR with variable exponent), and (2) its value should depend on the specific charge; only if the exponent of the power law $x_{P}=$ const $/ q^{\kappa}$ is constant in some percentile interval, then the RR exponent might not depend on $q$, but it would still need to vary at different percentiles. This fundamental discrepancy with the experimental evidence lies at the core that the RR function with a single $n$ value is a poor description of the fragmentation data, and a severe hindrance for its use in state-of-the-art fragmentation prediction models.

The $x_{P}$ versus specific charge convergent lines pattern (which we call 'fan' plots) is a general characteristic of fragmentation by blasting. In fact, most of the groups of data that form the basis for this work show the same behavior as the data in Fig. 2; power laws fit the percentile size data to the powder factor quite well, and the exponent 
is a function of $P$. In well-controlled model-scale blasts, this behavior is extremely well developed; the consequences of that are discussed in Ouchterlony et al. (2016).

The facts above are not described by any known credible theory of blast fragmentation that favors a specific fragment size distribution. On the contrary, they speak in favor of developing prediction equations for blast fragmentation that do not depend on any specific size distribution function. Size and passing data have a clear physical meaning, whereas shape, or uniformity, indices are just a reduced interpretation of the data through some particular size distribution. A median, or a 20 percentile size, even a 63.2 percentile like $x_{\mathrm{c}}$, have their full meaning without any additional statement; however, a shape index has no real meaning unless it is tied to a particular distribution-a RR, a Swebrec, a lognormal, a maximum-size-transformed RR one, etc.

\section{The Model Foundations}

Ouchterlony's (2009b) blasting-related interpretation of Holsapple and coworkers' work on asteroid collisions (Holsapple and Schmidt 1987; Housen and Holsapple 1990) has already been mentioned. From the dimensional analysis, Ouchterlony arrives at the following expression for the fraction $P$ of fragments of mass less than $m$ :

$P=F_{1}\left(\frac{m}{M}, \Pi_{\mathrm{s}}, \Pi_{\mathrm{g}}\right)$

where $M$ is the total nominal mass fractured; $\Pi_{\mathrm{s}}$ and $\Pi_{\mathrm{g}}$ are strength- and gravity-related non-dimensional parameters; and $F_{1}$ is an unspecified functional dependence.

The mass of a fragment is $m=k_{1} \rho x^{3}, x$ being size and $k_{1}$ a particle shape factor. The nominal mass broken for each explosive charge, for the case of bench blast, is generally approximated as $M=\rho \mathrm{BHS} / \cos \theta, \theta$ being the holes inclination angle with respect to the vertical. Introducing a (as yet undetermined) characteristic blast size $L_{\mathrm{c}}, M=k_{2} r L_{\mathrm{c}}^{3}$, with $k_{2}$ a blast geometry or bench shape factor:

$k_{2}=\frac{\mathrm{BHS}}{L_{\mathrm{c}}^{3} \cos \theta}$

Equation 15 becomes:

$P=F_{1}\left(\frac{k_{1} x^{3}}{k_{2} L_{\mathrm{c}}^{3}}, \Pi_{\mathrm{s}}, \Pi_{\mathrm{g}}\right)$

Neglecting the gravity parameter (that, for the case of asteroids, applies to bodies for which the material strength is less than the gravitational self-compressive strength which, obviously, does not apply to Earth) and solving Eq. 17 for $x / L_{\mathrm{c}}$ :

$$
\frac{x}{L_{\mathrm{c}}}=F_{2}\left(P, \frac{k_{1}}{k_{2}}, \Pi_{\mathrm{s}}\right)
$$

The strength factor $\Pi_{\mathrm{s}}$ has the following expression (Ouchterlony 2009b, Eq. 7b, adapted from Housen and Holsapple 1990, Eq. 40):

$\Pi_{\mathrm{s}}=E_{M}\left(\frac{\sigma^{*}}{\rho}\right)^{3 \mu /(\tau-2)} L_{\mathrm{s}}^{-3 \mu(\lambda+\tau) /(\tau-2)} \mathrm{e}^{(3 \mu-2) / 2}\left(\frac{\rho}{\rho_{e}}\right)^{1-3 v}$

where $E_{M}$ is impact energy per target mass, clearly related to the powder factor in rock blasting; $\sigma^{*}$ is a rock strength quantity with dimension [stress][length $]^{\lambda}[\text { time }]^{\tau} ; e$ is the explosive energy per unit mass; ${ }^{6} \rho_{e}$ is impactor density which is transposed in the blasting model as the explosive density; ${ }^{7}$ and $L_{\mathrm{s}}$ is a characteristic length (in the collision model, it is the target radius) that we will choose for simplicity equal to $L_{\mathrm{c}}{ }^{8}{ }^{8}$ The constants $\mu, v, \lambda$ and $\tau$ are to be determined experimentally. $\mu$ and $v$ describe the impactor coupling to the target; the two extremes of the coupling are energy-scaled impacts $(\mu=2 / 3, v=1 / 3)$ and momentumscaled ones $(\mu=1 / 3, v=1 / 3)$. Holsapple and Schmidt (1987) show that the case of a point source explosion has $\mu=2 / 3$ and that collisions on non-porous targets, including rocks, are governed by $\mu$ close to 0.6 , whereas porous targets (such as dry sand) have $\mu=0.37-0.40$, close to the momentum limit. Selecting thus the energy-scaled interaction for the blasting case analogy in Earth's rock:

$\Pi_{\mathrm{s}}=E_{M}\left(\frac{\sigma^{*}}{\rho}\right)^{2 /(\tau-2)} L_{\mathrm{c}}^{-2(\lambda+\tau) /(\tau-2)}$

$\lambda$ and $\tau$ are material constants that describe the dependence of the strength on the scale of the target and the loading rate, respectively. Loading rate in blasting can, in principle, be described by the rise time of the pressure in the borehole, or the reaction time in the detonation front. This time is proportional to the ratio of the length of the reaction zone to the average sound speed of the detonation products in the reaction zone (Price 1981); in homogeneous explosives such as straight emulsions, it can range from less than

\footnotetext{
${ }^{6}$ The collision model uses impact velocity $U$, dimensionally equal to the square root of energy per unit mass (hence the dividing factor 2 in the exponent of $e$ that does not exist when $U$ is used). Note that the impact energy per unit impactor mass for a typical collision velocity of some $\mathrm{km} / \mathrm{s}$ is some $\mathrm{MJ} / \mathrm{kg}$, of the same order of magnitude that energies per unit mass of explosives.

${ }^{7}$ Having equated the velocity squared of the impactor to the explosive energy per unit mass, the density of the impactor plays the same role as the explosive density since, for both, the driving energy is formally density $\times$ volume $\times$ energy per unit mass.

${ }^{8} L_{c}$ is also an equivalent block length (actually the edge length of the cube with equal volume); choosing this or an equivalent sphere radius would only mean a different value for the shape factor $k_{2}$.
} 
$100 \mathrm{~ns}$ to about $1 \mu \mathrm{s}$, depending on the size of the sensitizing microspheres (Hirosaki et al. 2002); for heterogeneous explosives such as ANFO or ANFO/emulsion mixtures, rise times in the order of $10 \mu \mathrm{s}$ have been reported (Onederra et al. 2011). Reaction time, or reaction zone thickness with which to estimate the reaction time using the reaction zone sonic velocity (that can be estimated from the detonation velocity), is never included in blasting reports so we have no way to assess its influence in the model. We are forced then, as a first approximation, to not consider the loading rate dependence, i.e., make $\tau=0$ in Eq. 20.

About the scale dependence, let us define $\bar{\sigma}$ as the strength (with dimensions of stress) of the rock mass of a certain size $\bar{R}$; we may write:

$\sigma^{*}=\bar{\sigma} \bar{R}^{\lambda}$

Assuming $\sigma^{*}$ invariant for a certain rock mass (which amounts to consider a classical power dependence of strength with size, Persson et al. 1994, quoting Weibull 1939; Jaeger and Cook 1969; Hoek and Brown 1980; Scholz 1990), the strength for a given size $R$ is:

$\sigma=\frac{\bar{\sigma}}{(R / \bar{R})^{\lambda}}$

Using Eq. 21 for $\sigma^{*}$ and making $\tau=0$ in Eq. 20 for a non-rate variable model:

$\Pi_{s}=E_{M}\left(\frac{\bar{\sigma} \bar{R}^{\lambda}}{\rho}\right)^{-1} L_{c}^{\lambda}$

Writing $E_{M}$ (energy per unit rock mass) in terms of the powder factor $q$ (mass of explosive per unit rock volume) and the explosive energy per unit mass $e, E_{M}=q e / \rho$, the factor $\Pi_{\mathrm{s}}$ becomes:

$\Pi_{\mathrm{s}}=\frac{q e}{\bar{\sigma}}\left(\frac{L_{\mathrm{c}}}{\bar{R}}\right)^{\lambda}$

The size of fragments for a given fraction passing $P$, or size quantile $P$, becomes, from Eq. 18:

$\frac{x}{L_{\mathrm{c}}}=F_{2}\left[P, \frac{k_{1}}{k_{2}}, \frac{q e}{\bar{\sigma}}\left(\frac{L_{\mathrm{c}}}{\bar{R}}\right)^{\lambda}\right]$

The Kuznetsov formula and others that have been proposed for the calculation of the fragments size (Langefors and Kihlström 1963; Holmberg 1974; Larsson 1974; Kou and Rustan 1993; Rustan and Nie 1987) generally agree that the central fragment size is a power function of the powder factor; plots as the ones in Fig. 2 say the same for other percentile sizes so this will be attempted here. Assuming a power form also for the other parameters and writing $\Pi_{\mathrm{s}}$ and the $k$-ratio as the reciprocals in Eq. 25, this becomes:
$\frac{x}{L_{\mathrm{c}}}=P^{r}\left(\frac{k_{2}}{k_{1}}\right)^{h}\left(\frac{\bar{\sigma} \bar{R}^{\lambda}}{q e L_{\mathrm{c}}^{\lambda}}\right)^{\kappa}=P^{r}\left(\frac{k_{2}}{k_{1}}\right)^{h}\left(\frac{\bar{\sigma}}{q e}\right)^{\kappa}\left(\frac{\bar{R}}{L_{\mathrm{c}}}\right)^{\lambda \kappa}$

The constants $r, h, \kappa$ and $\lambda$ are to be determined from experimental data. Note that they are not universal for all percentages passing since that would lead to a GatesGaudin-Schuhmann distribution (Gates 1915; Gaudin 1926; Schuhmann 1940), with exponent $1 / r$ :

$P=\left(\frac{x}{x_{\max }}\right)^{1 / r} ; \quad x_{\max }=\left(\frac{k_{2}}{k_{1}}\right)^{h}\left(\frac{\bar{\sigma}}{q e}\right)^{\kappa} L_{\mathrm{c}}^{1-\lambda \kappa}(\bar{R})^{\lambda \kappa}$

The $P$-dependence of $\kappa$ is already stated in Sect. 1 (Fig. 2), and the variation of $r$ follows from the fact that the $\log -\log$ slope of the cumulative size distribution is known to vary across the percentage passing range. In fact, Eq. 27 could be thought of as a piecewise log-log linear representation of the size distribution in which the top size and the slope vary constantly across the size range.

The fragments shape factor $k_{1}$ is an experimental variable that is generally unknown so it will be considered as one more parameter (that, in principle, may also vary with the size of the fragments, hence with the percentile). Thus, for each percentage passing $P$, the group $P^{r} / k_{1}^{h}$ can be considered a single parameter, $k$ (which should tend to zero with $P$ ). Assuming arbitrarily that the strength parameter $\bar{\sigma}$ corresponds to a unit size (in the same units as those used for $L_{\mathrm{c}}$ ) of rock mass, $\bar{R}=1$, Eq. 26 is, finally:

$\frac{x_{P}}{L_{\mathrm{c}}}=k k_{2}^{h}\left(\frac{\bar{\sigma}}{q e}\right)^{\kappa} \frac{1}{L_{\mathrm{c}}^{\lambda \kappa}}$

The size has been written $x_{P}$ to show that it is the percentile $P$ size. This model requires the calibration of the four functions $k(P), h(P), \kappa(P)$ and $\lambda(P)$ which, together with the selection of the strength variable $\bar{\sigma}$ and the characteristic size $L_{\mathrm{c}}$, will be accomplished from experimental data.

\section{The Data}

Fragmentation data from bench blasting have been gathered for a total of 169 blasts published in the literature. Some of them were small-scale (half to $1 \mathrm{~m}$ bench height) tests, and others were full-scale production blasts; all of them were carried out in the field on natural rock mass. For all of them, the fragmentation data were obtained by sieving and weighing of a sample of the muckpile, and the description of the blasts and the rock mass was reasonably detailed so that calculations of the Kuz-Ram type made in Sect. 1, and likewise of the model presented here, can be carried out. Table 1 lists the mine and quarry sites and the sources of the data; Table 2 gives a general description of 
Table 2 Fragmentation data

\begin{tabular}{|c|c|c|c|c|c|c|c|c|}
\hline \multirow[t]{2}{*}{ Blast site } & \multirow[t]{2}{*}{ No. blasts } & \multirow[t]{2}{*}{$n_{p}$} & \multirow[t]{2}{*}{$x_{\min }(\mathrm{mm})$} & \multirow[t]{2}{*}{$x_{\max }(\mathrm{mm})$} & \multirow[t]{2}{*}{$P_{\min }(\%)$} & \multirow[t]{2}{*}{$P_{\max }(\%)$} & \multicolumn{2}{|l|}{ Amount sieved } \\
\hline & & & & & & & $t$ per blast & $\%$ \\
\hline El Alto, Spain & 1 & 14 & 0.1 & 1500 & 0.017 & 100 & 481 & 2 \\
\hline Mt. Coot-tha, Australia & 1 & 5 & 5.0 & 1000 & 2.5 & 100 & 32 & 0.05 \\
\hline Bårarp, Sweden & 7 & $19-20$ & 0.075 & $500-1000$ & $0.1-0.6$ & 47.9-98.7 & $247-490$ & 100 \\
\hline Kållered, Sweden & 6 & 17 & 0.075 & 2000 & $0.34-0.49$ & 100 & $3660-5638$ & 100 \\
\hline Billingsryd, Sweden & 6 & 19 & 0.074 & 2360 & $0.76-1.03$ & 100 & $10,087-12,898$ & 100 \\
\hline Rolla, MO, USA (Otterness et al.) & 29 & $6-8$ & 9.525 & $229-457$ & $7.9-20.6$ & 100 & $0.5-10.5$ & 100 \\
\hline High Forest, MN, USA & 20 & $7-8$ & 4.7625 & $229-559$ & $1.03-3.86$ & 100 & $0.9-2.0$ & 100 \\
\hline Guan Shan, China & 8 & 11 & 100 & 1500 & $4.7-11.4$ & 100 & $4.3-9.3$ & 100 \\
\hline Rolla, MO, USA (Stagg and Nutting) & 18 & $7-8$ & 4.7625 & $304.8-609.6$ & $2.8-7.4$ & 100 & $0.7-2.8$ & 100 \\
\hline Waterloo, IA, USA & 7 & $4-5$ & $31.8-57.15$ & $608-738$ & $18.4-27.5$ & $89.4-95.3$ & $141-730$ & $11-100$ \\
\hline St Paul Park, MN, USA & 6 & 5 & 31.8 & $562-584$ & $27.5-30.7$ & $96.7-97.9$ & $92-270$ & $34-100$ \\
\hline Granite Falls, MN, USA & 3 & 5 & 31.8 & $543-579$ & $22.8-31.7$ & $96.9-99.2$ & $280-413$ & $3-5$ \\
\hline Manitowoc, WI, USA & 6 & 5 & 22.2 & $653-825$ & $17.9-22.4$ & $89.8-95.5$ & $130-325$ & $5.5-13$ \\
\hline Vändle, Sweden & 4 & 19 & 0.063 & 1000 & $0.50-1.11$ & 100 & $98-122$ & $0.6-0.9$ \\
\hline Långåsen, Sweden & 6 & 19 & 0.063 & 1000 & $0.78-1.10$ & 100 & $94-413$ & $0.5-1.1$ \\
\hline Rolla, MO, USA (Smith) & 20 & 7 & 4.7625 & 304.8 & $1.7-9.7$ & $48-89.5$ & $0.4-2.4$ & 100 \\
\hline Rolla, MO, USA (Brinkmann) & 13 & 7 & 4.7625 & 304.8 & $2.24-7.20$ & $65.1-90.2$ & $1.2-2.8$ & 100 \\
\hline Rolla, MO, USA (Bleakney) & 8 & 7 & 4.7625 & 304.8 & $1.56-7.7$ & $74.1-94.3$ & $1.6-3$ & 100 \\
\hline
\end{tabular}

$n_{p}$, no. of data points per curve; $x_{\min }, x_{\max }$, minimum and maximum size (where $P_{\max }$ is not $100 \%, x_{\max }$ is a log-log extrapolated value to $P=100 \%) ; P_{\min }, P_{\max }$, minimum and maximum percentage passing

Table 3 Rock properties

\begin{tabular}{|c|c|c|c|c|c|c|c|c|c|}
\hline Blast site & Density $\left(\mathrm{kg} / \mathrm{m}^{3}\right)$ & $E(\mathrm{GPa})$ & $\sigma_{\mathrm{c}}(\mathrm{MPa})$ & $c_{P}(\mathrm{~m} / \mathrm{s})$ & $s_{j}(\mathrm{~m})$ & $j_{\mathrm{o}}$ & $\sigma_{\mathrm{c}}^{2} /(2 E) \mathrm{MPa}$ & RMD & $A$ \\
\hline El Alto, Spain & 2560 & 64 & 119 & 2994 & 2.4 & 0.25 & 0.11 & $\mathrm{~J}$ & 7.7 \\
\hline Mt. Coot-tha, Australia & 2730 & 82.5 & 200 & 5766 & 0.5 & 0.75 & 0.24 & $\mathrm{~J}$ & 10.1 \\
\hline Bårarp, Sweden & $2660-2670$ & 82.5 & 237 & 5525 & 4.0 & 0.5 & 0.34 & M & $6.8-6.9$ \\
\hline Kållered, Sweden & 2690 & 34.5 & 168 & $5525^{\mathrm{a}}$ & 0.47 & 1.0 & 0.41 & $\mathrm{~J}$ & 8.9 \\
\hline Billingsryd, Sweden & 2945-2972 & 44.7 & 252 & $4088-4107^{\mathrm{a}}$ & 0.97 & 0.75 & 0.71 & $\mathrm{~J}$ & $8.9-9.0$ \\
\hline Rolla, MO, USA & $2650-2677$ & 15.0 & 62 & $4496-4511$ & 0.29 & 0.25 & 0.13 & $\mathrm{~J}$ & 3.1 \\
\hline High Forest, MN, USA & 2700 & $50.0-55.7$ & $143-155$ & $5742-5766$ & 0.10 & 0.25 & $0.20-0.21$ & $\mathrm{~J}$ & $3.8-4.7$ \\
\hline Guan Shan, China & 2560 & 27.0 & 112 & 3896 & 1.5 & 1.0 & 0.23 & M & 4.4 \\
\hline Waterloo, IA, USA & $2674-2701$ & $57^{\mathrm{a}}$ & $131^{\mathrm{a}}$ & $3208-3922$ & 0.53 & 0.25 & 0.15 & $\mathrm{~J}$ & 8.0 \\
\hline St Paul Park, MN, USA & $2677^{\mathrm{a}}$ & $15^{\mathrm{a}}$ & $62^{\mathrm{a}}$ & $2228-3627$ & 0.34 & 0.25 & 0.13 & $\mathrm{~J}$ & 6.7 \\
\hline Granite Falls, MN, USA & $2670^{\mathrm{a}}$ & $36^{\mathrm{a}}$ & $166^{\mathrm{a}}$ & $4420^{\mathrm{a}}$ & 0.20 & 0.5 & 0.38 & $\mathrm{~J}$ & 4.1 \\
\hline Manitowoc, WI, USA & $2677^{\mathrm{a}}$ & $15.0^{\mathrm{a}}$ & $62^{\mathrm{a}}$ & $3050^{\mathrm{a}}$ & 2.0 & 0.25 & 0.13 & M & 4.3 \\
\hline Vändle, Sweden & 2640 & 70.3 & 207 & 5612 & 0.5 & 0.75 & 0.31 & $\mathrm{~J}$ & 10.0 \\
\hline Långåsen, Sweden & 2677 & 67 & 206 & 5275 & $0.75-4.5$ & 0.5 & 0.32 & $\mathrm{~J}$ & $7.7-9.5$ \\
\hline Overall range & $2560-2972$ & $15.0-83.0$ & $62-252$ & $2228-5766$ & $0.10-4.5$ & $0.25-1.0$ & $0.11-0.71$ & $\mathrm{~J}-\mathrm{M}$ & $3.1-10.1$ \\
\hline
\end{tabular}

$E$, Young's modulus; $\sigma_{\mathrm{c}}$, uniaxial compressive strength; $c_{P}$, longitudinal wave velocity; $s_{j}$, mean joint spacing; $j_{\mathrm{o}}$, joint orientation index (as defined in Sect. 4); RMD, Kuz-Ram's rock mass description (J: jointed, M: massive); A, Kuz-Ram's rock factor (Eq. 6)

${ }^{a}$ Not reported in the sources; values estimated

the size distribution data; Tables 3, 4 and 5 give relevant rock and blast design variables.

Elastic modulus is sometimes reported in the sources as from laboratory tests (static), and sometimes as calculated from P- and S-wave velocities, which results in somewhat different figures; the original value quoted in each case has been retained. This adds some uncertainty, or unwanted variability, to the data, that would probably not be 
Table 4 Blast design data. Explosives and initiation systems

\begin{tabular}{|c|c|c|c|c|c|c|c|c|c|}
\hline Blast site & Explosive type $^{\mathrm{a}}$ & $\begin{array}{l}\text { Density } \\
\left(\mathrm{g} / \mathrm{cm}^{3}\right)\end{array}$ & $\begin{array}{l}\text { VOD } \\
(\mathrm{m} / \mathrm{s})\end{array}$ & $e(\mathrm{MJ} / \mathrm{kg})$ & $Q(\mathrm{~kg})$ & $q\left(\mathrm{~kg} / \mathrm{m}^{3}\right)$ & $q e(\mathrm{MPa})$ & $\Delta t(\mathrm{~ms})$ & $\begin{array}{l}\text { Detonator } \\
\text { type }\end{array}$ \\
\hline El Alto, Spain & ANFO-Al & 0.8 & 4029 & 4.84 & 224 & 0.45 & 2.18 & 42 & Non-el \\
\hline $\begin{array}{l}\text { Mt. Coot-tha, } \\
\text { Australia }\end{array}$ & Watergel & 1.2 & 5447 & 4.01 & 119 & 0.52 & 2.08 & 25 & Non-el \\
\hline Bårarp, Sweden & Emulsion & $1.2-1.225$ & $5000-5851$ & $\begin{array}{c}1.27^{\mathrm{b}}- \\
3.20\end{array}$ & $5.5-19$ & $0.42-0.47$ & $0.59-1.51$ & 25 & Electronic \\
\hline Kållered, Sweden & Emulsion & $1.3^{\mathrm{c}}$ & $2707-5470$ & 2.90 & $45-54$ & $0.46-0.63$ & $1.34-1.82$ & 42 & Non-el \\
\hline Billingsryd, Sweden & Emulsion & $1.3^{\mathrm{c}}$ & $3234-5638$ & 2.90 & $109-157$ & $0.69-0.84$ & $1.99-2.43$ & $25-42$ & Non-el \\
\hline Rolla, MO, USA & Dynamite & 1.12 & 2560 & 2.94 & $0.05-1.1$ & $0.43-1.22$ & $1.26-3.57$ & $1.7-5.8$ & Seismic $^{d}$ \\
\hline $\begin{array}{l}\text { High Forest, MN, } \\
\text { USA }\end{array}$ & Dynamite & 1.12 & 2560 & 2.94 & $0.05-0.07$ & $0.23-0.51$ & $0.69-1.50$ & $0-25$ & Electric \\
\hline Guan Shan, China & Dynamite & 0.93 & 3010 & $1.76^{\mathrm{b}}$ & 0.52 & 0.67 & $1.17-1.18$ & $0-1.9$ & Non-el $^{\mathrm{e}}$ \\
\hline Rolla, MO, USA & Dynamite & 1.12 & 2560 & 2.94 & 0.14 & $0.43-0.62$ & $1.27-1.82$ & $0-45$ & $\mathrm{EBW}^{\mathrm{f}}$ \\
\hline Waterloo, IA, USA & $\begin{array}{l}\text { ANFO, Emulsion, } \\
\text { Dynamite }\end{array}$ & $0.81-1.34$ & $3840-5578$ & $2.94-3.89$ & $28-39$ & $0.42-0.57$ & $1.32-1.91$ & 12 & Electronic \\
\hline $\begin{array}{l}\text { St Paul Park, MN, } \\
\text { USA }\end{array}$ & Dynamite & 1.12 & 4330 & 2.94 & 12.2 & $0.50-0.51$ & $1.48-1.49$ & $2-48$ & Seismic $^{\mathrm{d}}$ \\
\hline $\begin{array}{l}\text { Granite Falls, MN, } \\
\text { USA }\end{array}$ & ANFO, Emulsion & $0.8-1.15$ & $4000-4830$ & $3.27-3.89$ & $102-173$ & $0.72-1.05$ & $2.79-3.76$ & $10-12$ & Electronic \\
\hline $\begin{array}{l}\text { Manitowoc, WI, } \\
\text { USA }\end{array}$ & ANFO, Emulsion & $0.8-1.2$ & $3800-4830$ & $3.27-3.89$ & $39-56$ & $0.75-1.00$ & $2.92-3.51$ & 13 & Electronic \\
\hline Vändle, Sweden & Emulsion & $1.17-1.23$ & $4718-4771$ & 3.34 & $77-93$ & $0.53-0.76$ & $1.77-2.53$ & 42 & Non-el \\
\hline Långåsen, Sweden & Emulsion & $0.98-1.15$ & 5110 & 3.25 & $85-116$ & $0.72-1.05$ & $2.35-3.43$ & $5-25$ & $\begin{array}{l}\text { Non-el, } \\
\text { Electronic }\end{array}$ \\
\hline $\begin{array}{l}\text { Rolla, MO, USA } \\
\text { (Smith) }\end{array}$ & Dynamite & 1.12 & 2560 & 2.94 & $0.03-0.14$ & $0.44-1.00$ & $1.30-2.95$ & $0-25$ & Electric \\
\hline $\begin{array}{l}\text { Rolla, MO, USA } \\
\text { (Brinkmann) }\end{array}$ & Dynamite & 1.12 & 2560 & 2.94 & 0.14 & $0.41-1.00$ & $1.22-2.95$ & $0-25$ & Electric \\
\hline $\begin{array}{l}\text { Rolla, MO, USA } \\
\text { (Bleakney) }\end{array}$ & Dynamite & 1.12 & 2560 & $\begin{array}{r}1.38^{\mathrm{b}}- \\
2.94\end{array}$ & $0.14-0.19$ & $0.45-0.65$ & $0.80-1.91$ & 25 & Electric \\
\hline Overall range & & $0.8-1.34$ & $2560-5851$ & $1.27-4.84$ & $0.03-224$ & $0.23-1.22$ & $0.59-3.76$ & $0-48$ & \\
\hline
\end{tabular}

VOD, detonation velocity; $e$, specific explosive energy (per unit mass); $Q$, charge per hole; $q$, powder factor or specific charge; $q e$, energy powder factor or explosive energy concentration; $\Delta t$, in-row delay

${ }^{a}$ Emulsion designates both straight and blend products

${ }^{b}$ Decoupled charges. Decoupling ratios (hole-to-charge diameter ratio): Bårarp 1.5, Guan Shan 1.31, Rolla (Bleakney): 1.06-1.5 (energy of the decoupled shots $2.61-1.38 \mathrm{MJ} / \mathrm{kg}$ )

${ }^{c}$ Mean charge density (includes dynamite as bottom charge, density $1.45 \mathrm{~g} / \mathrm{cm}^{3}$ )

Precisions for nonstandard systems (not reported for electric, non-electric or electronic)

d $0.11 \mathrm{~ms}$

e The delay was given by different lengths of shock tube

${ }^{\mathrm{f}}$ Exploding bridge wire. Precision: $\max (0.0025 \%$ delay time, $50 \mathrm{~ns})$

overcome very much by the estimation of one from the other by grossly approximate formulae (e.g., Eissa and Kazi 1988). In some cases, some properties have been estimated from the data available using, e.g., elastic relations or properties of similar rocks. These are marked in Table 3.

The explosive energy is rated as the heat of explosion value, both for it being a well-defined magnitude, that does not depend much on the detonation thermodynamic code and on the products expansion assumptions, and for being a property commonly specified by the manufacturers; this is the same approach as the Kuz-Ram model in which the explosive energy is rated by means of the relative weight strength, a measure of the heat of explosion with respect to ANFO. Other explosive energy values such as the useful work could indeed be used, but the 
Table 5 Blast design data. Other dimensional and non-dimensional parameters

\begin{tabular}{|c|c|c|c|c|c|c|c|c|c|c|}
\hline Blast site & $d(\mathrm{~mm})$ & $B(\mathrm{~m})$ & $H(\mathrm{~m})$ & $S(\mathrm{~m})$ & $l_{\mathrm{c}}(\mathrm{m})$ & $S / B$ & $\begin{array}{l}\sqrt{\mathrm{HS}^{\mathrm{a}}} \\
(\mathrm{m})\end{array}$ & $c_{P} \Delta t / S^{\mathrm{b}}$ & $\frac{B}{\sqrt{H S}} \cos \theta^{c}$ & $\begin{array}{l}\text { No. } \\
\text { rows }\end{array}$ \\
\hline El Alto, Spain & 142 & 5.00 & 18.6 & 6.00 & 15.8 & 1.20 & 10.56 & 21.0 & 0.48 & 1 \\
\hline Mt. Coot-tha, Australia & 102 & 3.80 & 14.0 & 4.30 & 12.1 & 1.13 & 7.76 & 33.5 & 0.46 & 4 \\
\hline Bårarp, Sweden & $38-76$ & $1.35-2.70$ & $5.0-5.3$ & $1.65-3.40$ & $3.7-4.4$ & $1.17-1.26$ & $2.93-4.12$ & $40.6-83.7$ & $0.46-0.66$ & 1 \\
\hline Kållered, Sweden & 76 & $2.60-2.90$ & $8.6-9.8$ & $2.9-3.3$ & $5.5-8.4$ & $1.00-1.23$ & $5.22-5.69$ & $70.3-80.0$ & $0.49-0.58$ & 3 \\
\hline Billingsryd, Sweden & 76 & $2.60-3.00$ & $16.4-19.5$ & $2.8-3.2$ & $16.8-19.2$ & $1.03-1.19$ & $7.13-7.90$ & $50.8-88.1$ & $0.35-0.43$ & 3 \\
\hline Rolla, USA (Otterness) & $11-25$ & $0.25-0.76$ & $0.43-2.26$ & $0.34-1.07$ & $0.4-1.9$ & $1.00-2.03$ & $0.48-1.55$ & $12.4-59.0$ & $0.34-0.79$ & 1 \\
\hline High Forest, MN, USA & 22 & $0.36-0.44$ & $0.70-0.90$ & $0.38-0.88$ & $0.3-0.5$ & $1.00-2.00$ & $0.56-0.84$ & $0-378.3$ & $0.48-0.68$ & 1 \\
\hline Guan Shan, China & 42 & $0.43-0.75$ & 1.4 & $0.75-1.30$ & 0.7 & $1.00-3.02$ & $1.02-1.35$ & $0-9.9$ & $0.32-0.73$ & 1 \\
\hline $\begin{array}{l}\text { Rolla, USA (Stagg and } \\
\text { Nutting) }\end{array}$ & 27 & 0.38 & 1.14 & $0.53-0.76$ & 1.0 & $1.40-2.00$ & $0.78-0.93$ & $0-379.3$ & $0.41-0.49$ & 1 \\
\hline Waterloo, IA, USA & 89 & 1.98 & 6.71 & 3.05 & $4.7-5.2$ & 1.54 & 4.52 & $12.6-15.4$ & 0.44 & 1,3 \\
\hline St Paul Park, MN, USA & 63.5 & 1.75 & 6.71 & 2.06 & 4.9 & 1.17 & 3.71 & $3.0-71.3$ & 0.47 & 1 \\
\hline Granite Falls, MN, USA & 140 & $3.05-3.35$ & $11.3-12.8$ & $3.96-4.88$ & $8.3-9.8$ & $1.30-1.46$ & $6.69-7.90$ & $10.8-11.2$ & $0.42-0.46$ & 3 \\
\hline Manitowoc, WI, USA & 89 & 1.98 & 8.23 & $2.99-3.20$ & $7.2-7.3$ & $1.52-1.62$ & $4.96-5.13$ & $12.4-13.3$ & $0.39-0.40$ & 3 \\
\hline Vändle, Sweden & 90 & $2.86-3.46$ & $10.8-12.7$ & $3.71-4.27$ & $10.3-12.0$ & $1.21-1.34$ & $6.58-7.22$ & $55.2-63.5$ & $0.43-0.52$ & 4 \\
\hline Långåsen, Sweden & 89 & $2.16-2.55$ & $12.9-16.7$ & $2.9-3.4$ & $12.9-16.6$ & $1.33-1.35$ & $6.12-7.54$ & $7.8-45.5$ & $0.32-0.38$ & 4 \\
\hline Rolla, USA (Smith) & 27 & $0.26-0.48$ & $0.38-1.14$ & $0,38-0.76$ & $0.25-1.0$ & $0.79-2.65$ & $0.38-0.93$ & $0-296$ & $0.31-1.26$ & 1 \\
\hline $\begin{array}{l}\text { Rolla, USA } \\
\text { (Brinkmann) }\end{array}$ & 27 & $0.34-0.38$ & 1.14 & $0.38-0.76$ & 1.0 & $1.00-2.08$ & $0.66-0.93$ & $0-296$ & $0.39-0.58$ & 1 \\
\hline Rolla, USA (Bleakney) & $15.9-19$ & $0.35-0.41$ & $1.14-1.45$ & 0.57 & $1.0-1.3$ & $1.41-1.64$ & $0.81-0.91$ & 197 & $0.38-0.50$ & 1 \\
\hline Overall range & $11-142$ & $0.25-5.00$ & $0.38-19.5$ & $0.34-6.00$ & $0.25-19.2$ & $0.79-3.02$ & $0.38-10.6$ & $0-379.3$ & $0.31-1.26$ & $1-4$ \\
\hline
\end{tabular}

$d$, hole diameter; $B$, burden; $H$, bench height; $S$, spacing; $l_{\mathrm{c}}$, charged length

${ }^{a}$ Characteristic length $L_{\mathrm{c}}$ in the model

b Non-dimensional delay factor $\Pi_{t}$ in the model

c Bench shape factor $k_{2}$ in the model

model would require a recalibration with them-a difficult task though, since useful work is often not given by the manufacturers and there is not a common ground for a standard calculation of it. When a heat of explosion value is not reported in the blast description, a value compatible with the type of explosive used has been assigned. In a few cases ( 9 blasts, their energies marked with $b$ in Table 4), decoupled charges were used; for these, the explosive energy used is the energy remaining in an isentropic expansion point at the expansion ratio equal to the ratio of the borehole volume to the charge volume. This energy has been calculated from the JWL isentropes determined in Sanchidrián et al. (2015) from cylinder test data for ANFO and emulsion-type explosives. Figure 3 shows the 'energy efficiency,' or the ratio of the remaining energy at a given expansion (described as decoupling ratio, hole-to-charge diameter ratio) to the energy at expansion ratio equal one (the fully coupled case). Except for some outlier, most of the expansion energy ratio curves are packed in a fairly narrow band so that, as a first estimation, the mean curve has been used for all decoupled shots (even for the case of dynamite for which no experimental expansion data are available).

\section{Model Fitting}

For each blast, the fragmentation data have been interpolated to determine the size percentiles between 5 and 100 . Linear interpolation in $\log -\log$ space has been used. Extrapolation has been allowed whenever the range of data does not cover the 5-100\% passing; however, a penalty has been applied to the extrapolated points in the fit so that their weight decreases as the extrapolation distance gets longer. The penalty function used is:

$w_{e}=e^{-0.5\left(r_{P}-1\right)^{3}}$

$r_{P}$ being the extrapolation ratio:

$r_{P}=e^{\left|\ln \left(P / P_{f}\right)\right|}$ 
Fig. 3 Fraction of energy remaining in the detonation products along expansion

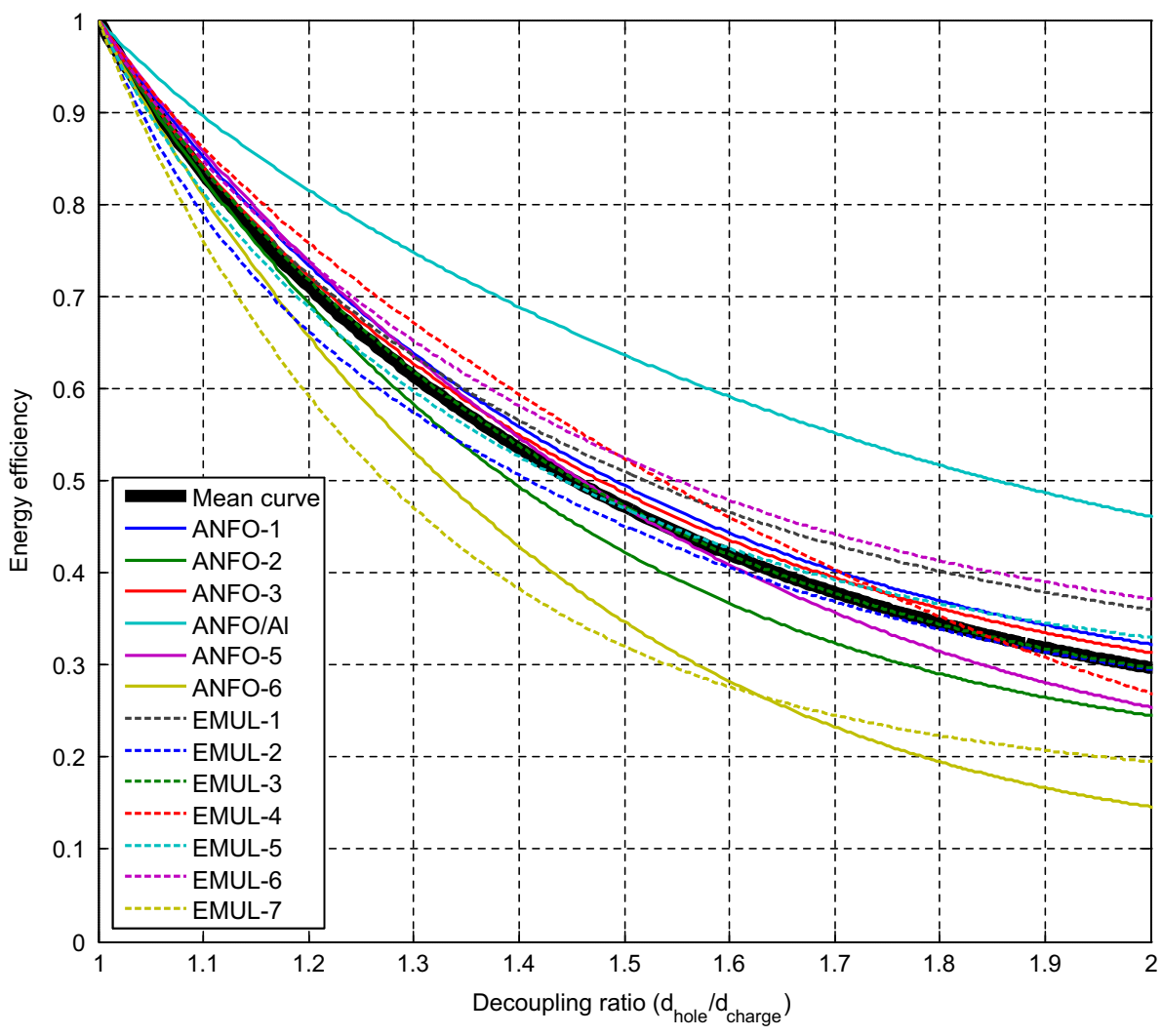

Table 6 Number of extrapolated points

\begin{tabular}{|c|c|c|c|c|c|c|c|c|c|c|c|c|}
\hline$P(\%)$ & 100 & 90 & 80 & 70 & 60 & 50 & 40 & 30 & 20 & 10 & 5 & 1 \\
\hline No. of interpolated data points & 99 & 122 & 141 & 161 & 164 & 166 & 169 & 167 & 149 & 125 & 96 & 26 \\
\hline No. of extrapolated points & 70 & 47 & 28 & 8 & 5 & 3 & 0 & 2 & 20 & 44 & 73 & 143 \\
\hline No. of extrapolated points with $r_{P}>2$ & 3 & 0 & 0 & 0 & 0 & 0 & 0 & 0 & 0 & 20 & 44 & 126 \\
\hline
\end{tabular}

where $P$ is the percentage passing at which the size is being calculated and $P_{f}$ is the lowermost (if $P<P_{f}$ ) or uppermost (if $P>P_{f}$ ) passing value with data. ${ }^{9}$ The minimum and maximum percentage passing for the different data groups that are listed $\left(P_{\min }\right.$ and $\left.P_{\max }\right)$ in Tables 2 and 6 gives the number of extrapolated points for each percentage passing; the large amount of extrapolated points below $P=5 \%$, with long extrapolations required, prevent from analyzing any lower percentile size.

Besides the extrapolation penalty, a size-dependent weight $w_{x}=1 /\left(x / L_{\mathrm{c}}\right)^{1 / 2}$ has been included in the least squares scheme, in order to allow a fair influence of the small data and to prevent the larger numbers to be too dominant in the overall error, while not penalizing the determination coefficient too much. The final weight of

\footnotetext{
${ }^{9}$ For example, if the lower size data of a distribution are at $P_{f}=20 \%$, then the value extrapolated at $P=10 \%$ has $r_{P}=2$, and a weight $w_{e}=0.607$; the value extrapolated at $P=5 \%$ has $r_{P}=4$ and $w_{e}=1 \times 10^{-6}$
}

each point is the smaller of the size-dependent weight (normalized to one) and the extrapolation penalty factor:

$w=\min \left(w_{e}, w_{x}\right)$

Equation 28 is fitted to the $x_{P}$ data values ${ }^{10}$ by means of a Levenberg-Marquardt (Seber and Wild 2003) nonlinear least squares method programmed in a MATLAB (2015) environment. Numerous minimizations (up to 1000 times the number of unknown parameters, and more than that in some particularly difficult cases) are run with variable starting parameters values until the minimum sum of squares is ensured, this way avoiding local minima as much as possible. The result for the 50 percentile sizes of the

\footnotetext{
${ }^{10}$ For each fit job, we have 169 data points (one from each fragmentation curve i.e. a blast). In principle, none of them is a measured value, but an interpolated one (or extrapolated if this is the case) at the relevant percentage. This way we can combine the data (available from each data set at different percentages passing) into a single percentile set of values. This adds an interpolation error to the experimental uncertainty of the data; this matter is revisited in Sect. 5.
} 


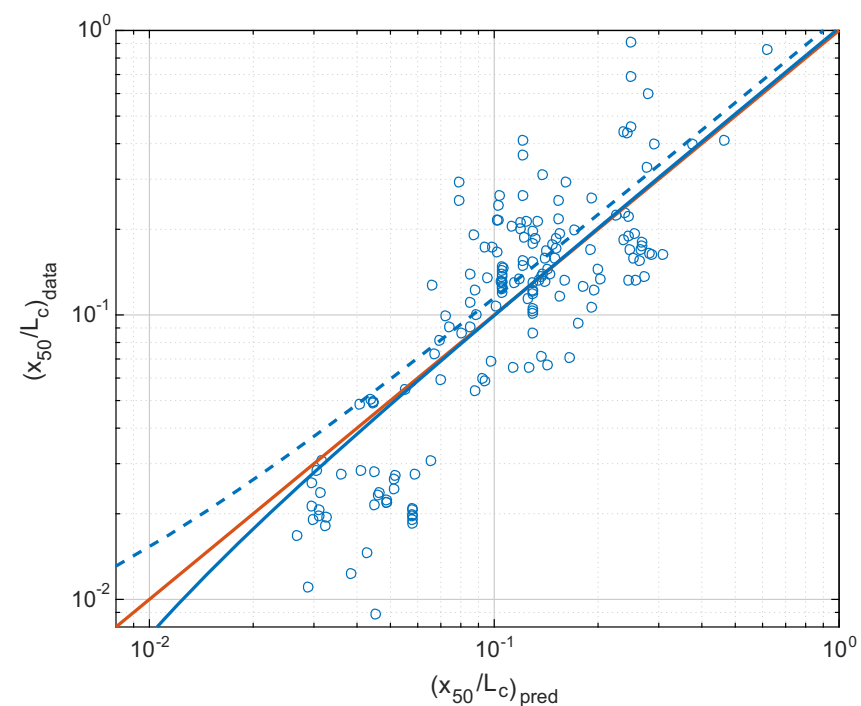

Fig. 4 Four-parameter model (Eq. 28) for $x_{50}$. Left data versus predicted values plot; the blue lines are the data versus predicted linear fit (dashed ordinary least squares, solid robust, least sum of absolute residuals); the orange line is the data $=$ predicted values

distributions data is a modest determination coefficient, $R^{2}=0.6413$.

Since the determination coefficient may be a misleading value in nonlinear regression, the relative root-meansquared error (RRMSE) and the median absolute log error (MALE) are also used as meaningful goodness-of-fit values, as they estimate the prediction capability of the model. The RRMSE is:

$\mathrm{RRMSE}=\sqrt{\mathrm{MSE}} / \operatorname{mean}\left(x_{P} / L_{c}\right)$

$M S E$ being the mean-squared error:

$\mathrm{MSE}=\frac{1}{n_{\mathrm{c}}-p} \sum_{i=1}^{n_{c}} w_{e i}\left[\left(x_{P, \text { pred }} / L_{\mathrm{c}}\right)_{i}-\left(x_{P, \text { data }} / L_{\mathrm{c}}\right)_{i}\right]^{2}$

$n_{\mathrm{c}}$ being the number of data points (i.e., the number of blasts) and $p$ the number of parameters. The extrapolation weights $w_{e i}$ are applied so that only errors of long extrapolated (hence dubious) points are downsized; the fit weights $w$ from Eq. 31 are not used so as not to give an unrealistic low value of the error. Let the logarithmic error of each predicted value be:

$e_{L i}=w_{e i} \ln \frac{\left(x_{P, \text { pred }}\right)_{i}}{\left(x_{P, \text { data }}\right)_{i}}$

where the extrapolation weights $w_{e i}$ are also applied here. The median absolute log error, MALE, expressed as relative error for better interpretation, $\mathrm{MALE}_{r}$, is:

$\operatorname{MALE}_{r}=\exp \left(\operatorname{median}\left|e_{L i}\right|\right)-1$

Both RRMSE and MALE indicate the relative deviation of the predicted values, MALE being more robust (since it is

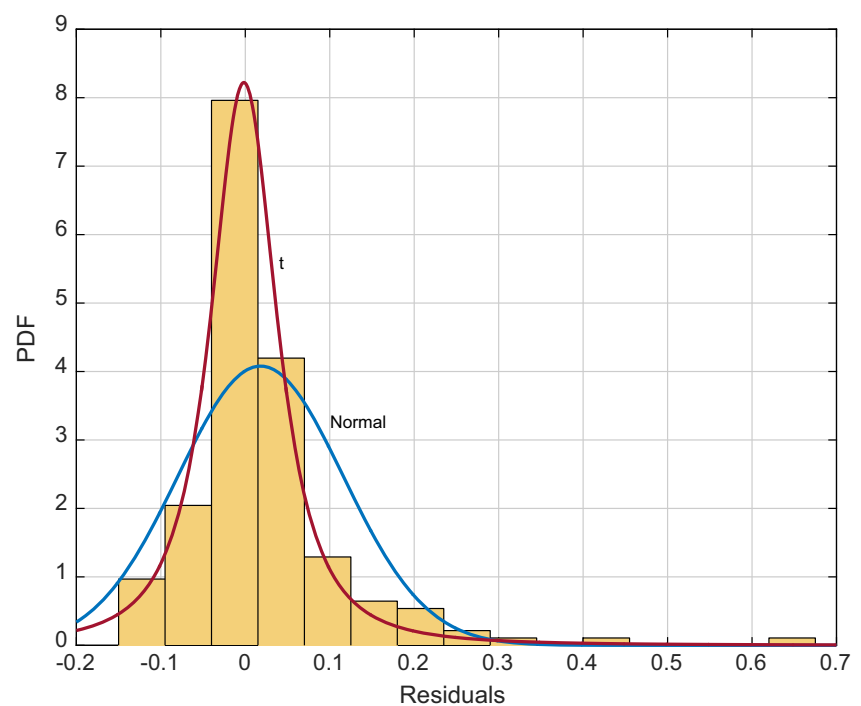

line. Right normalized histogram of residuals; the two PDF functions shown are normal (blue) and $t$ (red), fitted to the distribution of residuals (color figure online)

a median) and symmetric with respect to zero. ${ }^{11}$ However, high RRMSE may indicate a large number of badly predicted cases (outliers) which may stay hidden with the MALE.

For the fit under study (Eq. 28, $x_{50}$ ), RRMSE $=0.6730$, MALE $_{r}=0.4498$. Although the determination coefficient and the errors are mediocre, the parameters of the model $(k=0.5932, h=1.2029, \kappa=0.2979, \delta=1.7740)$ are statistically significant with narrow confidence intervals, $p$ values $8 \times 10^{-7}, 6 \times 10^{-10}, 1 \times 10^{-4}$ and $2 \times 10^{-4}$, respectively. Figure 4 shows the predicted values versus data plot and the distribution of residuals; the latter shows some positive skew, highlighted by the normal and $t$ distributions fitted. The mean is 0.018 and the $95 \%$ coverage interval is $[-0.119,0.256]$. In summary, the model, effectively, translates a significant relation between the variables, but there must be other factors of variation that are not accounted for.

At least two influential characteristics that are relevant to rock blasting are missing from Eq. 28, since they do not apply to asteroid collisions:

1. The rock mass discontinuities The important geotechnical information is neither included in the bench shape factor $k_{2}$ nor in the fragments shape factor $k_{1}$. Using a classical approach (Lilly 1986, 1992; Scott 1996), the discontinuities are described by means of a combination of a spacing $J_{\mathrm{s}}$ and an orientation $J_{\mathrm{o}}$ term:

\footnotetext{
11 A predicted value ten times the data value has the same log error as a predicted value one tenth (though with opposite sign), while relative errors for that case are 9 and -0.9 ; this downsizing of the negative errors prevents a fair statistics with relative errors.
} 
$J_{\mathrm{F}}=J_{\mathrm{s}}+J_{\mathrm{o}}$

The joint spacing term is formulated as a non-dimensional ratio $s_{j} / L_{j}$, where $s_{j}$ is the discontinuity mean spacing and $L_{j}$ a characteristic size, selected as the variable (with dimensions of length) giving a higher determination for the model (see the end of this section). A limiting value $a_{s}$ is required for large joint spacing:

$J_{\mathrm{s}}=\min \left(\frac{s_{j}}{L_{j}}, a_{\mathrm{s}}\right)$

The joints orientation term $J_{\mathrm{o}}$ is defined as:

$J_{\mathrm{o}}=a_{\mathrm{o}} j_{\mathrm{o}}$

where $j_{\mathrm{o}}$ is Lilly's joints orientation index normalized to one (listed in Table 3) in order to give it, in principle, a similar weight as the spacing term, though the relative importance of each one will be finally cast by the constant $a_{\mathrm{o}}$, to be determined from the data. The joints orientation term describes the relative difficulty of the blast to break the toe for different joint orientations with respect to the face: $j_{\mathrm{o}}=0.25$ (horizontal), 0.5 (dipping out of the face), 0.75 (sub-vertical striking normal to the face) and 1 (dipping into the face or no visible jointing).

2. The delay Unlike asteroid collisions, rock blasting is carried out in multiple loadings taking place at successive times for neighboring shots so that there is wave and crack growth interference in the rock mass between two shots in the firing sequence. The general blasting knowledge, confirmed with experimental evidence, states that fragmentation improves (i.e., the size of the fragments decreases) when time is allowed for the cracks from a hole to propagate and damage the rock before the next hole detonates (Winzer et al. 1983; Katsabanis and Liu 1996; Cunningham 2005, referring data by Bergmann et al. 1974; Katsabanis et al. 2006, 2014; Johansson and Ouchterlony 2013). The time for the cracks to propagate is a function of their velocity and that is often normalized by dividing by the P-wave velocity $c_{P}$ (Roberts and Wells 1954; Dulaney and Brace 1960). In linear elastic materials, the theoretical upper limit of the crack velocity is the Rayleigh wave velocity (Freund 1972), which lies around $90 \%$ of the shear wave velocity, though measured crack speeds in rock are hardly in excess of half that velocity (Daehnke et al. 1996; Fourney 2015). Physically, the P-wave velocity determines the time of the first wave arrival from a neighboring blast hole; its use is convenient since, unlike the Rayleigh wave velocity (or the more difficult to know crack velocity), it is a commonly available, easy to determine and often reported, property for a given rock mass. Thus, the non-dimensional delay factor is defined as:

$\Pi_{t}=\frac{c_{P} \Delta t}{L_{t}}$

where $\Delta t$ is the in-row delay and $L_{t}$ is a characteristic length (to be selected with the same criterion as the other characteristic lengths, $L_{c}$ and $L_{j}$, see the end of this section). ${ }^{12} \Pi_{t}$ indicates how large the drill pattern (represented by the characteristic size $L_{t}$ ) is with respect to the travel distance of the longitudinal waves during a delay period. With $\Pi_{t}$ defined by Eq. 39, a power form for it cannot hold since it would lead to a zero size for an instantaneous blast if the exponent is positive, or infinite if negative (as should be since the fragment size diminishes with increasing delay). A suitable form of the $\Pi_{t}$ function could be an exponential:

$f_{t}\left(\Pi_{t}\right)=e^{-\delta \Pi_{t}}$

Inserting now the discontinuities term in Eq. 28:

$\frac{x_{P}}{L_{\mathrm{c}}}=k\left[\min \left(\frac{s_{j}}{L_{j}}, a_{\mathrm{s}}\right)+a_{\mathrm{o}} j_{\mathrm{o}}\right] k_{2}^{h}\left(\frac{\bar{\sigma}}{q e}\right)^{\kappa} \frac{1}{L_{\mathrm{c}}^{\lambda \kappa}}$

When Eq. 41, a six-parameter function, is fitted to $x_{50}$, the determination coefficient grows to $R^{2}=0.8504$, and the other two goodness-of-fit parameters reduce to RRMSE $=0.4270$, MALE $_{r}=0.1873$, all coefficients significant (maximum $p$ value $5 \times 10^{-4}$ ). Inserting now the delay term, Eq. 40:

$\frac{x_{P}}{L_{\mathrm{c}}}=k\left[\min \left(\frac{s_{j}}{L_{j}}, a_{\mathrm{s}}\right)+a_{\mathrm{o}} j_{\mathrm{o}}\right] k_{2}^{h}\left(\frac{\bar{\sigma}}{q e}\right)^{\kappa} \frac{1}{L_{\mathrm{c}}^{\lambda \kappa}} f_{t}\left(\Pi_{t}\right)$

$R^{2}=0.8549$, RRMSE $=0.4141$, MALE $_{r}=0.2116$, all coefficients significant. The improvement of the quality figures is marginal considering the increase in one parameter of the model MALE $_{r}$ even increases). This, together with a moderately high $p$ value for $\delta$ (though still within the 0.05 limit, $p=0.015$ ), could indicate that the exponential may not be the right form for the delay factor.

If the ratios $x_{\text {data }} / x_{\text {pred }}$ of Eq. 41 (the function without a delay term) are plotted against $\Pi_{t}$, the result is that of Fig. 5 (left graph); the aspect of this plot suggests a time function decreasing with the time factor down to a minimum, beyond which the function grows toward a constant value. Previous published work supports this behavior (Cunningham 2005, referring to data by Bergmann et al. 1974; Katsabanis et al. 2006, 2014; Johansson and Ouchterlony 2013; Katsabanis and Omidi 2015), though the existence of either a minimum or a lower asymptote is somewhat controversial (Katsabanis

\footnotetext{
12 Note that this non-dimensional form of the delay does not differ much from Cunningham's (2005) $\Delta t / T_{\max }$, where the characteristic length is the burden.
} 

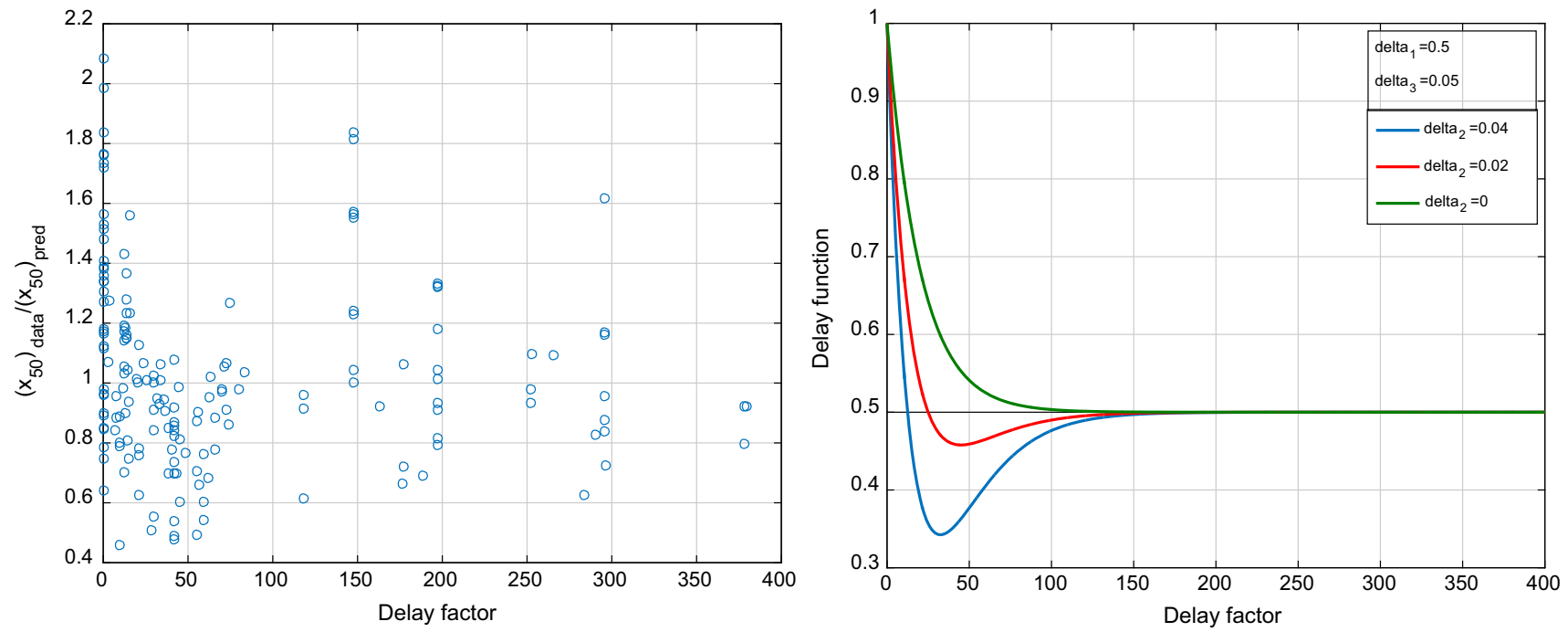

Fig. 5 Left error ratios of a model without delay factor (Eq. 41). Right Sample delay factors as in Eq. 43

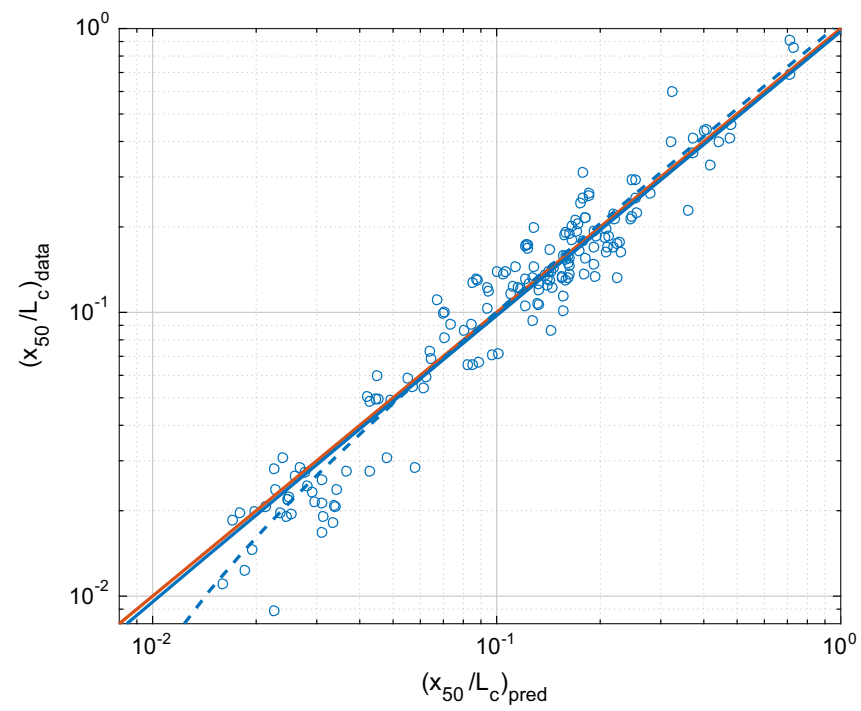

Fig. 6 Nine-parameter model (Eq. 41 with delay function Eq. 43) for $x_{50}$. Left data versus predicted values plot; the blue lines are data versus predicted linear fits (dashed ordinary least squares, solid robust, least sum of absolute residuals); the orange line is the

and Omidi 2015 suggest a minimum for the median size, though not so for the 20 percentile). Consequently, a time function has been sought that decreases with increasing delay with the possibility of having a minimum. Such function can be the following:

$f_{t}\left(\Pi_{t}\right)=\delta_{1}+\left(1-\delta_{1}-\delta_{2} \Pi_{t}\right) e^{-\delta_{3} \Pi_{t}}$

$\delta_{1}, \delta_{2}$ and $\delta_{3}$ being constants to be determined from the fit; $f\left(\Pi_{t}\right)$ is 1 at $\Pi_{t}=0$ (the case of simultaneous initiation of holes), decreases to a minimum at $\Pi_{t}=1 / \delta_{2}+1 / \delta_{3}-\delta_{1} /$ $\delta_{2}$ and then grows toward an asymptotic value $\delta_{1}$ for long delays (see Fig. 5, right). Equation 43 can also represent a

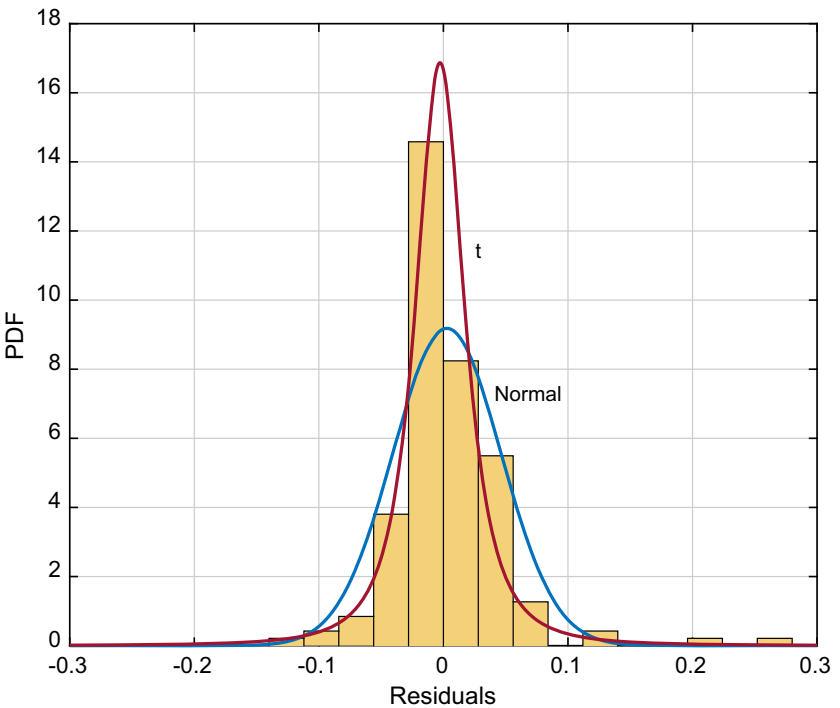

data $=$ predicted values line. Right normalized histogram of residuals; the two PDF functions shown are normal (blue) and $t$ (red), fitted to the distribution of residuals (color figure online)

decay toward a lower asymptote at $\delta_{1}$ without a minimum if $\delta_{2}=0$, see Fig. 5 (right). Using this delay function leads to $R^{2}=0.9242$, RRMSE $=0.2992$, MALE $_{r}=0.1840$, the nine coefficients strongly significant: the highest $p$ value is $2 \times 10^{-4}$. Such low $p$ values (lower than those for Eq. 41 , having increased the number of parameters by three) are an outstanding result, a consequence of the narrow confidence intervals of the coefficients, and speak strongly in favor of the delay function in Eq. 43. Figure 6 (left) shows the predicted values versus data plot; Fig. 6 (right) shows the histogram of residuals with normal and $t$ distributions superimposed. The distribution is nearly zero-centered and 


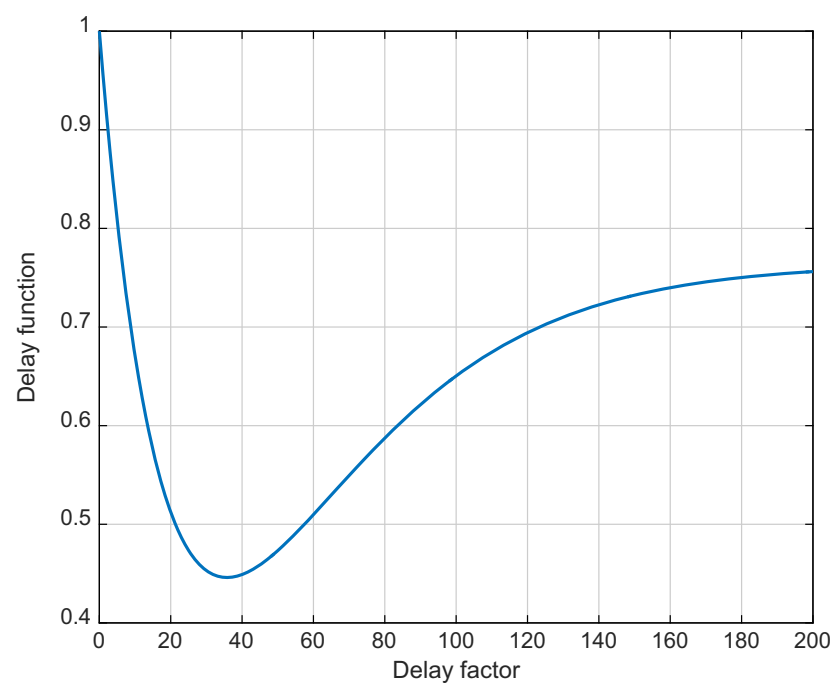

Fig. 7 Delay function (Eq. 43) for $x_{50}$

much narrower than the basic, four-parameter one in Fig. 4, with mean 0.0028 , still slightly skewed with $95 \%$ coverage $[-0.064,0.093]$. Figure 7 shows the delay function.

Many possible characteristic lengths $L_{c}$ have been tested (burden, spacing, bench height, stemming length, charged length and geometric means of their pairs); the geometric mean of bench height and spacing has been observed to generally provide a best fit of the final model: $L_{c}=(H \cdot S)^{1 / 2}$. The shape factor $k_{2}$ from Eq. 16 is then:

$k_{2}=\frac{\mathrm{BHS}}{(\mathrm{HS})^{3 / 2} \cos \theta}=\frac{B}{\sqrt{\mathrm{HS}} \cos \theta}$

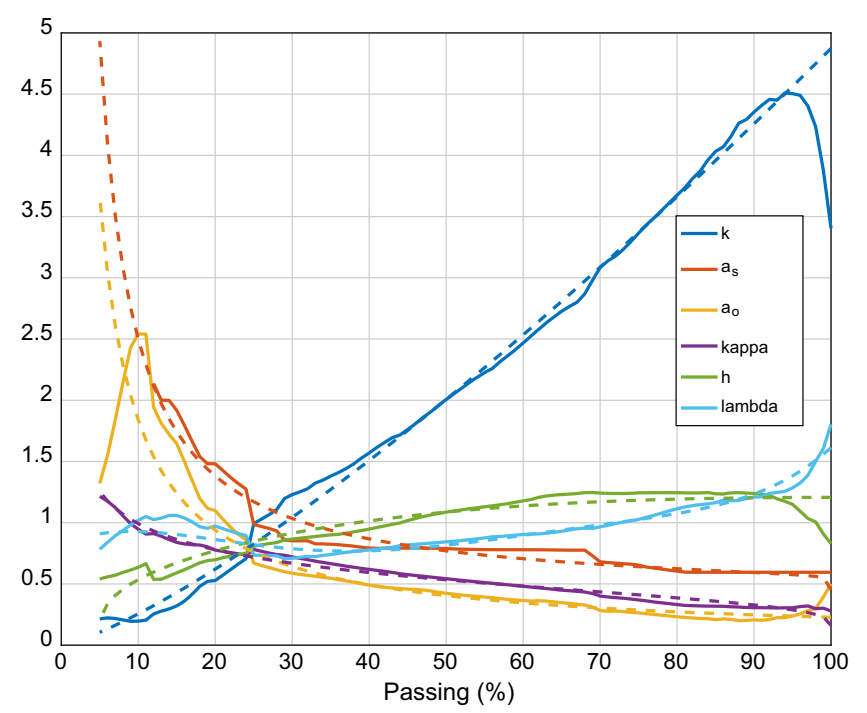

The characteristic lengths for non-dimensionalizing the joints spacing and the delay have also been selected from tests with different lengths; the best fits are obtained with the burden for the joints spacing term and the holes spacing for the delay factor: $L_{j}=B, L_{t}=S$.

About the strength factor $\bar{\sigma}$, several rock properties have been tested, and the ratio $\sigma_{c}^{2} /(2 E)$ - the elastic strain energy at rupture per unit volume-has finally been chosen as the one giving the most favorable fits to the data. This energy appears in Griffith's (1921) energy balance of linear elastic fracture mechanics, in which the strain energy released by a crack equals the elastic strain energy.

\section{Results and Discussion}

The function in Eq. 42 with the delay function $f_{t}\left(\Pi_{t}\right)$ in Eq. 43 has been fitted to percentiles from 100 to 5 . The parameters are plotted in Fig. 8 as functions of the percentage passing. Table 7 summarizes some quality figures of the fits. Note that the $p$ values are very low for all parameters and all percentiles, which indicate very tight confidence intervals, an outstanding result for a nine-parameter model fit.

For ease of application of the model, approximating functional forms have been derived for the nine parameters as functions of $P$. The result is summarized in Table 8 , and the $P$-functions are plotted in Fig. 8 as dashed lines. Note that not all the functions are direct fits to the parameters; functions for $k, \kappa$ and the delay parameters are fitted first, and then, the model is adjusted again to the other parameters, for which analytic functions of $P$ are finally obtained.

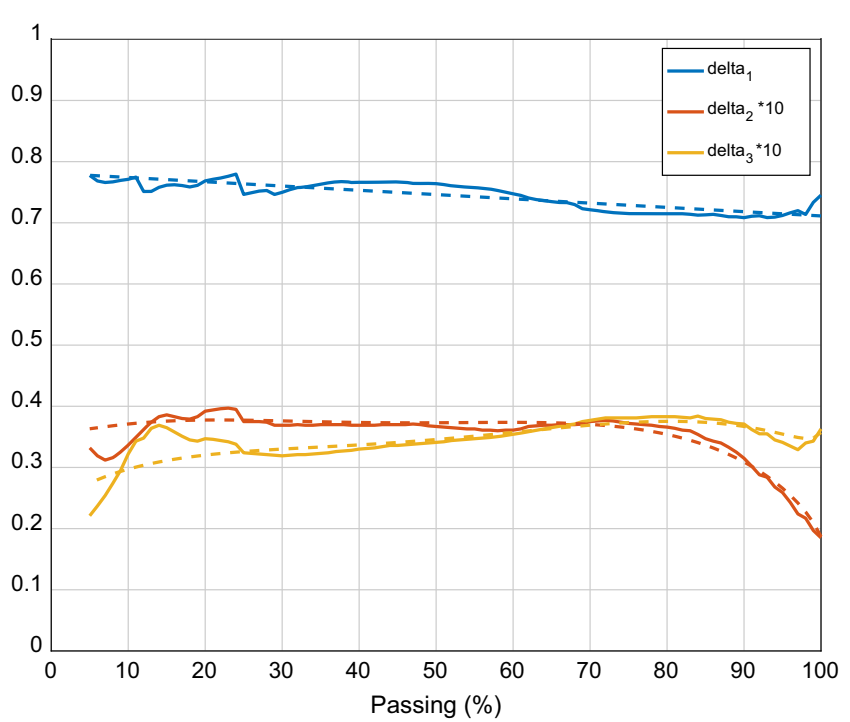

Fig. 8 Parameters of the model. Left $k, a_{\mathrm{s}}, a_{\mathrm{o}}, \kappa, h$ and $\lambda$. Right parameters of the delay function. Solid lines model fit results; dashed lines approximated functions 


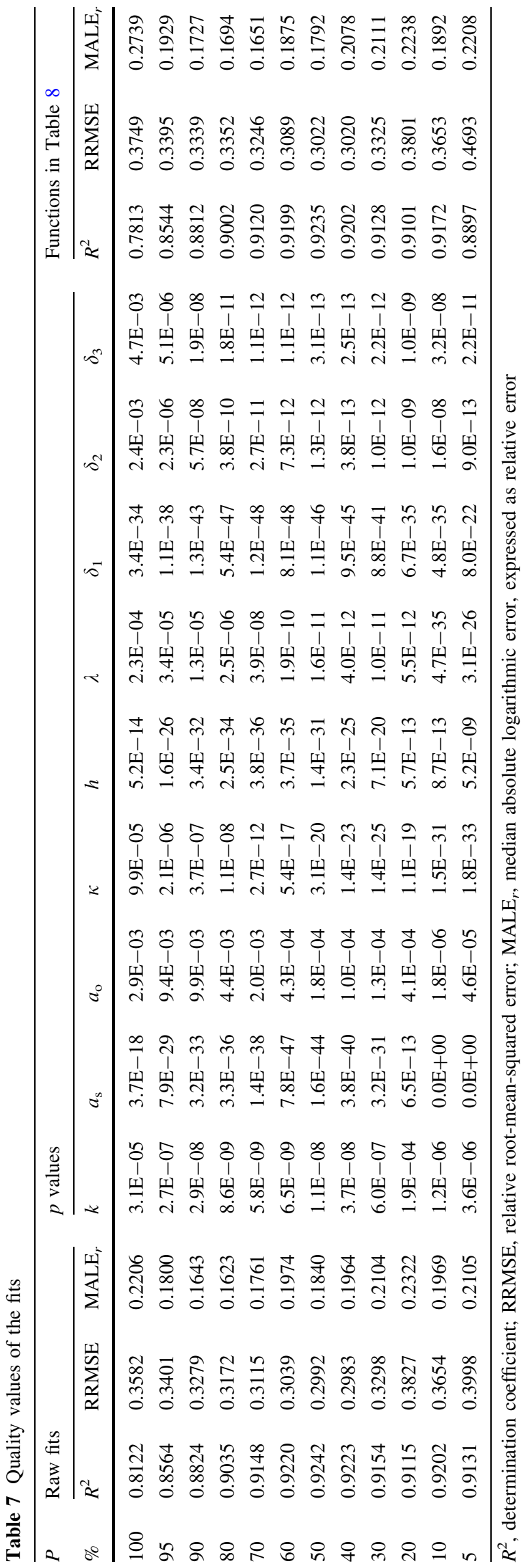

This two-step procedure allows to correct the errors from the fits in the first step, which otherwise might combine to give, in some cases, odd results. $k$, being $P^{r} / k_{1}^{h}$, has been chosen a monotonic function of $P$ since the fragments shape factor is likely not to change much with $P$. In doing this, we assume that the observed decrease in $k$ at high $P$ is not a strong result (just as the mild increase below $P=10 \%)$ and is due to inaccuracies, always greater at high and low percentages passing. The functional form of $\kappa(P)$ is also assumed a priori, and it will be revisited below.

Figure 9 shows the resulting set of delay functions for the different percentages passing.

The overall goodness of the fits is assessed in Fig. 10 where boxplots of logarithmic errors (as defined in Eq. 34) are plotted for the calculations using both the raw parameters from the fits and the functions of Table 8 . The penalty for using Table 8 formulae with respect to using the raw parameter values is small. The prediction error is $50 \%$ of the times less than about $25 \%$ in nearly the whole range both with the raw parameters and with their fitting functions. The boxplots in Fig. 10 are equivalent to those in Fig. 1 for the Kuz-Ram and crush zone models (in fact, log errors in Fig. 1 are also $w_{e}$-corrected, as in Eq. 34). The comparison of both is self-explanatory.

Another way of assessing the errors is in terms of the median (used for robustness) error of the size calculation for each data set, in absolute value; for $i=1, \ldots, n_{c}, n_{c}$ being the number of data sets (169):

$e_{L i}=\operatorname{med}\left|e_{L i j}\right|, \quad j=1, \ldots, 20$

where $e_{L i j}$ are log errors (as in Eq. 34) of the size at passing $P_{j}=5,10, \ldots, 100$. The distribution of these errors, expressed as relative errors, $\exp \left(e_{L i}\right)-1$, is given as boxplots in Fig. 11. This confirms an expected error of the percentile size prediction in the range of $20 \%$. Plots are also shown for the Kuz-Ram and crush zone models, the median error of which (i.e., the expected error) is about $60 \%$.

The 20-25\% expected errors of the model should be viewed in the context of fragment size measurements. All data used were obtained by sieving and weighing samples of the muckpile-in many cases a large fraction of that, encompassing large amounts of material. Sampling, screen processing and weighing a large amount of rock fragments in field conditions is a hard task prone to errors. The sampling must be done on a significant fraction of the muckpile and from the different zones in it; loader sampling and dumping techniques, and end effects in the pile, are responsible for shifts in the size distributions (Stagg and Rholl 1987); the type of sieve (square, rectangular, grizzly, etc.) has an influence on the screening results; losses of material due to overweights (not loadable onto the screen), projections, fines, etc. also introduce errors. 


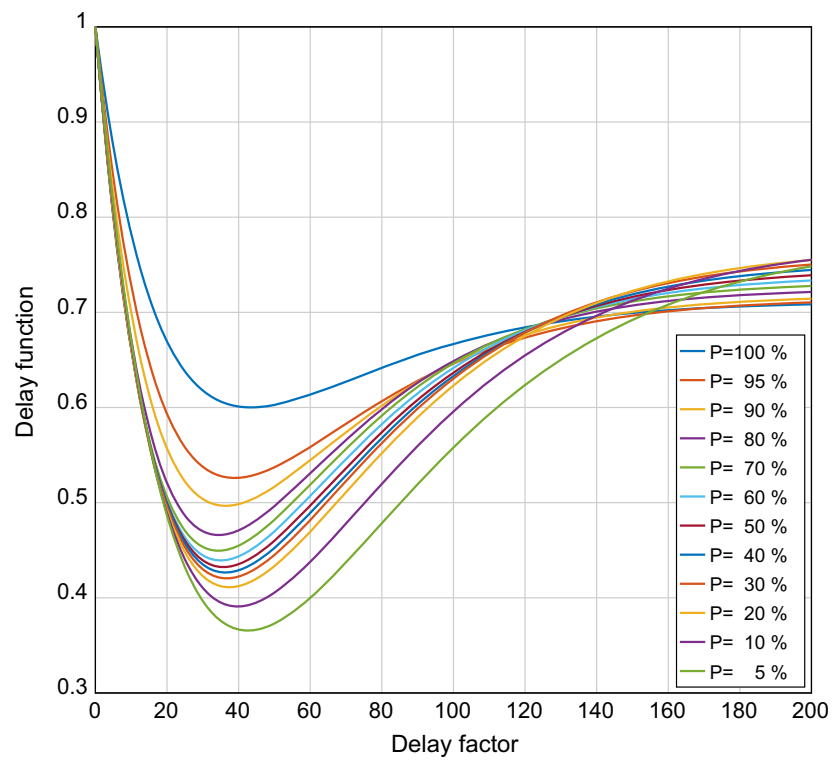

Fig. 9 Delay functions (Eq. 43, with coefficients from Eqs. 51-53)

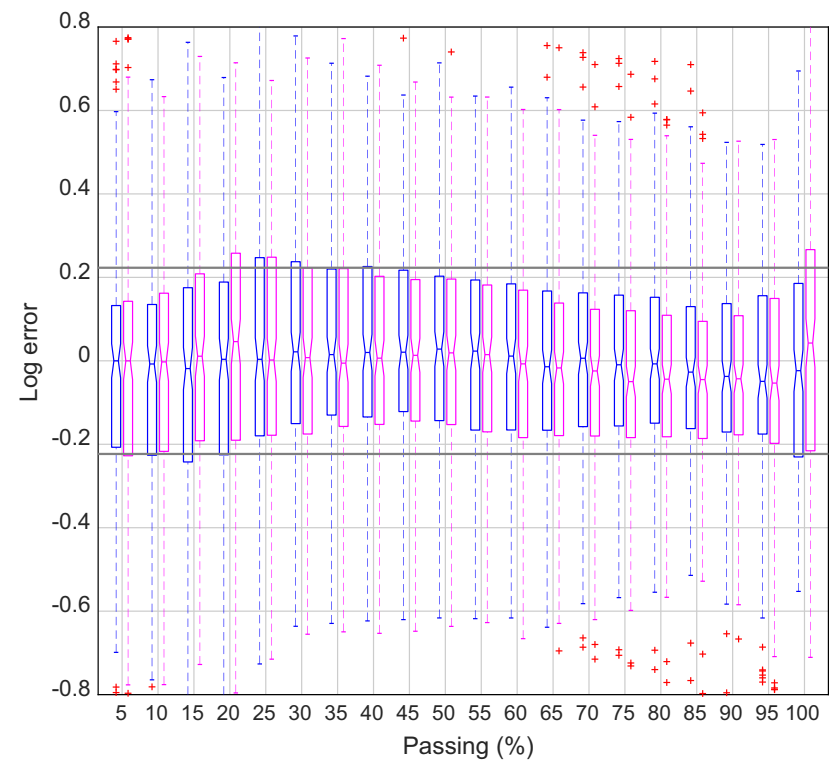

Fig. 10 Boxplots of logarithmic errors (Eq. 34) of the calculated percentiles. Blue boxes are the errors using the raw parameters, and magenta boxes are the errors using the functions in Table 8 . The gray horizontal lines are plotted at $\pm \ln 1.25$, equivalent to relative errors of $25 \%$ (color figure online)

Since the data come from different sources, a general statement on the error of the data is difficult to give, nor is it usually assessed by the authors. Sanchidrián (2015) estimated the uncertainty of the data by calculating the differences of equal percentile sizes of pairs of similar blasts (i.e., blasts in the same mine or quarry with equal, or very close, blast design ${ }^{13}$ ) for which fragmentation should be (ideally) the same; such differences are a combined measure of the uncertainty of the fragmentation

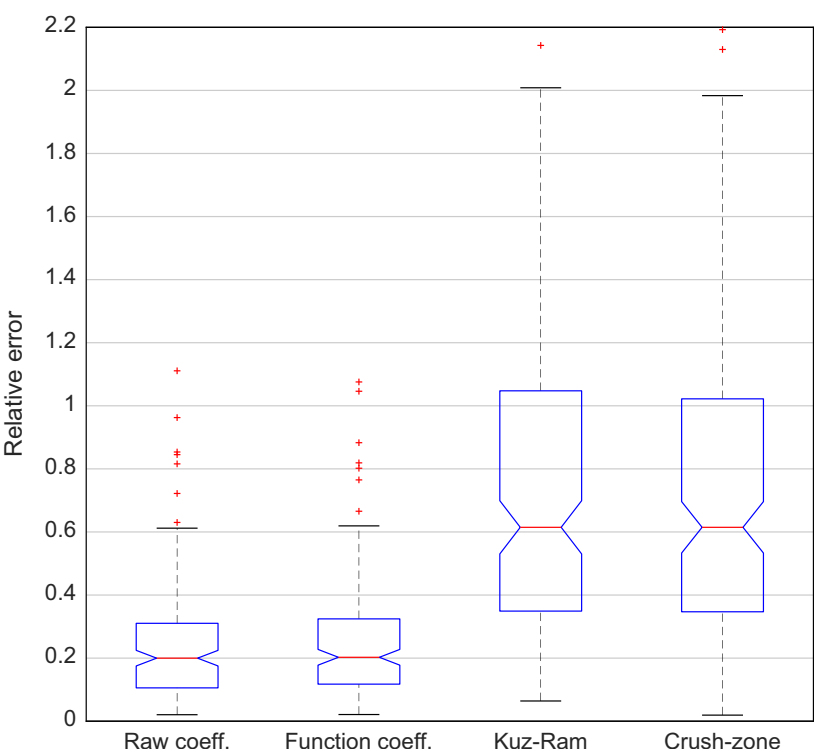

Fig. 11 Distributions of the medians of the absolute errors for all percentiles for each data set (Eq. 54, transformed to relative errors)

measurement (due to sampling, sieving and weighing), the variability of the phenomenon and the uncertainty of the blasting data. To all those, the calculation of sizes at some given percentages passing adds an interpolation error. The median differences for percentiles 5-100 was found to be between 8 and $22 \%$. Even if this is only a rough estimation of the uncertainty, and does not include possible systematic measurement errors, it gives an idea of how much accuracy we should be prepared to demand from a fragmentation prediction model, as there is no way we can have a better knowledge of the actual fragmentation than what the measurements give us.

Figure 12 shows some sample size distribution curves calculated, compared with the data; the $P$-functions for the model parameters are used. Each graph shows distributions for which the relative errors are around the first quartile, the median and the third quartile, plus one more in which the three best and the three worst predicted distributions, as from the median absolute value of the log error, are plotted.

One of the ideas that inspired this fragment size distribution model in which the exponent of the powder factor is

\footnotetext{
13 The concept 'equal blast design' is itself somewhat ambiguous since it is often difficult to determine the blasting parameters exactly; for instance, the powder factor, unless an extremely careful explosive mass and dimensional monitoring of the blasted rock is implemented, can have a certain variation for two seemingly identical blasts due to small variations of the blast hole diameter (bit wear), the bench height and burden, or the explosive density; delay time with pyrotechnic delay systems is also an undetermined variable; minor variations in the rock properties from one blast to another also make up for uncertainty in the fragmentation, etc.
} 
Table 8 Functional forms of the parameters; $P$ is fraction passing, $0.05 \leq P \leq 1$

\begin{tabular}{lll}
\hline$k=4.873 P^{1.280}$ & $(45)$ & $R^{2}=0.9993(\mathrm{R}) ; \mathrm{RRMSE}=0.0169$ \\
$a_{\mathrm{s}}=0.4539+0.1557 P^{-1.123}(1-P)^{0.1}$ & $(46)$ & $R^{2}=0.9873(\mathrm{R}) ; \mathrm{RRMSE}=0.0389$ \\
$a_{\mathrm{o}}=0.05431+0.1737 P^{-1.012}$ & $(47)$ & $R^{2}=0.9949(\mathrm{O}) ; \mathrm{RRMSE}=0.0707$ \\
$\kappa=0.161+0.373\left(\frac{1}{P}-1\right)^{0.3648}$ & $(48)$ & $R^{2}=0.9772(\mathrm{O}) ; \mathrm{RRMSE}=0.0610$ \\
$h=1.207(P-0.04744)^{0.3152(1-P)^{1.25}}$ & $(49)$ & $R^{2}=0.9683(\mathrm{O}) ; \mathrm{RRMSE}=0.0417$ \\
$\lambda=0.8201+2.773 P-22.33 P^{2}+59.62 P^{3}-65.06 P^{4}+25.79 P^{5}$ & $(50)$ & $R^{2}=0.9335(\mathrm{O}) ; \mathrm{RRMSE}=0.0564$ \\
$\delta_{1}=0.7811-0.06989 P$ & $(51)$ & $R^{2}=0.7337(\mathrm{O}) ; \mathrm{RRMSE}=0.0158$ \\
$\delta_{2} \delta_{3}=0.000836+0.003832 P-0.0137 P^{2}+0.0217 P^{3}-0.012 P^{4}$ & $(52)$ & $R^{2}=0.7528(\mathrm{O}) ; \mathrm{RRMSE}=0.0776$ \\
$\frac{\delta_{2}}{\delta_{3}}=P^{-0.09161}(1.01-P)^{0.2062} \exp (0.3034 P)$ & $(53)$ & $R^{2}=0.9733(\mathrm{R}) ; \mathrm{RRMSE}=0.0237$
\end{tabular}

$R^{2}$, determination coefficient; RRMSE, relative root-mean-squared error

$(\mathrm{R})$ and $(\mathrm{O})$ indicate robust and ordinary least squares fit, respectively

variable with $P$ was the 'fan' pattern we referred to in Sect. 1 (Ouchterlony et al. 2016). If extrapolated toward very low (away from the feasible range) powder factor, the different percentile lines often converge (more or less precisely) in a focal point. The data used for the fits happen to meet that 'fan' pattern more than well (see the upper graphs of Fig. 13; the energy concentration is used instead of the charge concentration used in Fig. 2). Even if the dispersion is very large (due to the great variation of scale, rock and shape factors, and delay), the coefficients of the fits (shown on the right plot) are significant, their $p$ values below $10^{-23}$ for the pre-factor and 0.03 for the exponent. The predicted results from the model also catch much of this behavior (Fig. 13, lower graphs; the $P$-functions for the parameters have been used for the calculation); the $p$ values of the coefficients (shown in the right plot) are less than $10^{-22}$ for the pre-factor and 0.02 for the exponent. As an exercise to confirm this, without any cross-influence, a sample calculation with constant blast characteristics (Table 9) and with the powder factor only variable (implemented by varying the hole diameter) has been done; the results are shown in Fig. 14 for three delay times; the fanlike convergence is clearly visible.

The functional form of $\kappa(P)$ (Table 8, Eq. 48) has been taken from the expression derived by Ouchterlony et al. (2016) for the exponent of the size versus powder factor power equations-i.e., the log-log slope of the fan-plot lines-following the hypothesis that the underlying distribution is a Swebrec function (Ouchterlony 2005a, b, 2009a) with shape parameter independent of the powder factor. The determination coefficient of the fit of Eq. 48 to the $P-\kappa$ values of the model is 0.9772 . This result provides an interesting link of the model presented here with the powder factor fan plots and the Swebrec distribution.

It is worth noting that the detonation velocity of the explosive is not among the variables of the model. The influence of detonation velocity in fragmentation is controversial: It appears only in the Kou and Rustan (1993) and Rustan and Nie (1987) formulae and is used in the crush zone model for the calculation of the borehole pressure; conversely, it is not present in the Kuz-Ram model (Cunningham 1983, 1987, 2005) and other fragmentation prediction formulae (Langefors and Kihlström 1963; Holmberg 1974; Larsson 1974; Chung and Katsabanis 2000).

In the present model, detonation velocity might influence the loading rate and the borehole pressure, both of which should in principle be relevant to fragmentation. Concerning the loading rate, the detonation velocity appears not to be the leading influence, since it varies in a relatively narrow range for most explosives used in rock blasting, while the reaction zone thickness appears to be much more important, as it varies in several orders of magnitude depending on the physical constitution and the sensitivity of the explosive. This is why explosives with not too different detonation velocity as, e.g., a straight emulsion and an emulsion/ANFO mixture have very different loading rates, as noted in Sect. 2.

About the borehole pressure, Boudet et al. (1996) gave the following expression of crack speed as function of the applied stress:

$v_{\mathrm{c}} / c_{\mathrm{R}}=b \sqrt{1-\frac{\Delta_{1}}{\Delta}}$

where $v_{\mathrm{c}}$ is crack speed, $c_{\mathrm{R}}$ is Rayleigh wave speed and $\Delta$ strain, $\Delta=P_{b} / E ; b$ and $\Delta_{1}$ are experimental constants, $b<1$. The borehole pressure can be estimated, for a coupled explosive, as half of the detonation pressure, which can be approximated from the explosive density and detonation velocity squared. Thus, a non-dimensional delay factor to more correctly account for the time of arrival of the cracks to the proximity of the next hole in the firing sequence would be: 

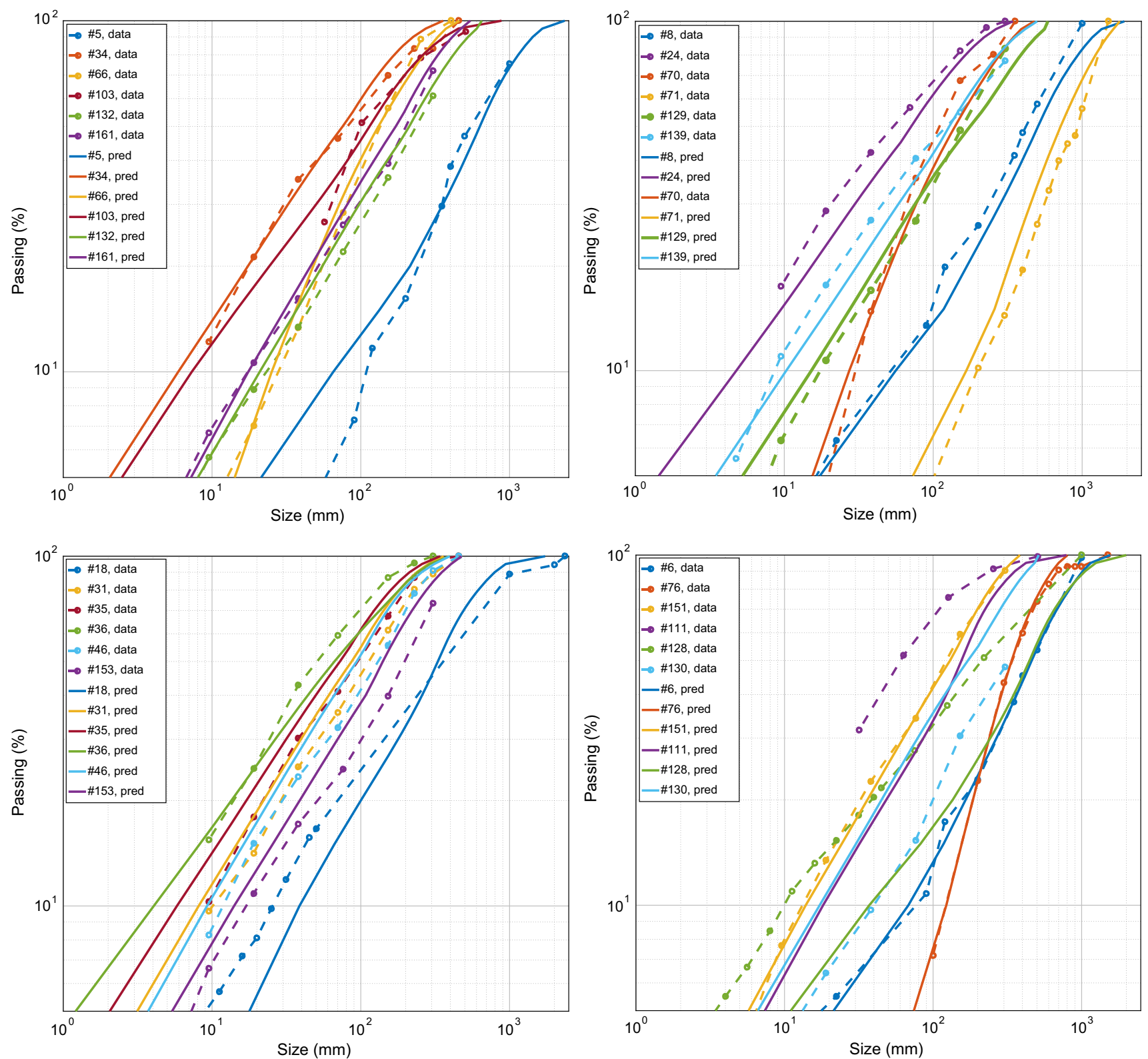

Fig. 12 Sample size distribution curves; dashed data, solid calculated. Median relative error of the curves plotted: upper left $11.0-12.6 \%$ (around the first quartile); upper right 19.4-21.0\%

$$
\Pi_{t}=\frac{c_{\mathrm{R}} \Delta t}{L_{t}} \sqrt{1-\frac{\Delta_{1}}{\rho_{e} D^{2} / E}}
$$

where $\Delta_{1}$, an unknown property of the rock, must, however, be left as a parameter of the fit. As pointed out in Sect. 4, the wave velocity reported in our data is the P-wave one, so that, in order to use Eq. 56, we must successively estimate the shear wave and the Rayleigh wave velocities. Tests with this delay factor were not satisfactory, perhaps due to the lack of precision of the Rayleigh wave velocity estimation or to the constant $\Delta_{1}$ assumption. (around the median); lower left $30.5-33.1 \%$ (around the third quartile); lower right $2.1-3.4 \%$ (the three best results), $88.3-107.6 \%$ (the three worst results)

A similar form to Eq. 56 but using directly the P-wave velocity instead of the Rayleigh wave one also failed. In summary, we have not been able to account for the two explosive/rock interaction processes on which detonation velocity could be influential. Perhaps better data, with a more detailed description of the detonation physics and the rock velocities, are required.

Other parameters that are not part of the model are:

- Number of rows Some of the variability in the data is probably due to this factor. Blasts used to fit the model were single and multi-row (see Table 5), with 3 or 4 

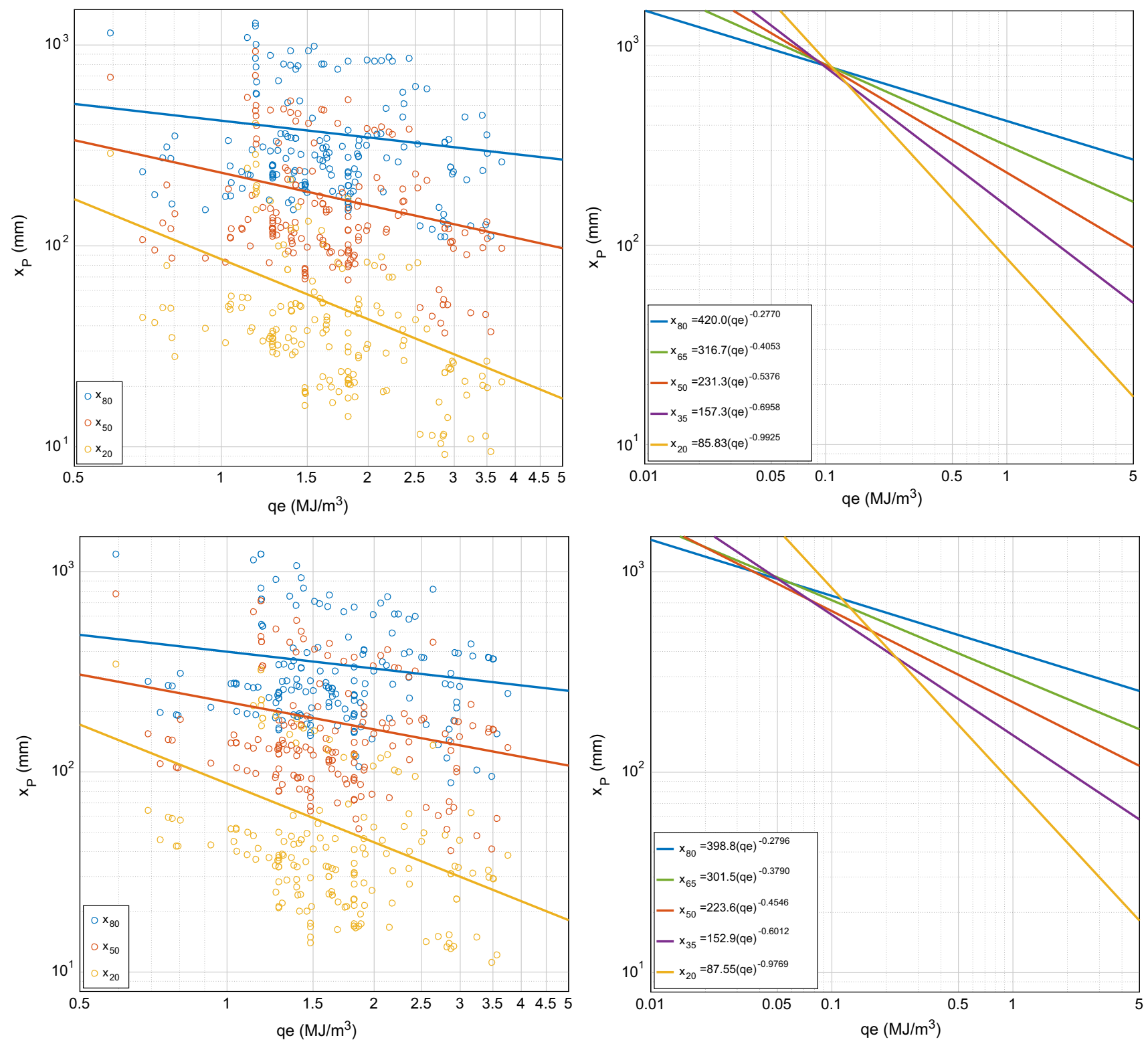

Fig. 13 'Fan plots' of percentile sizes versus energy powder factor. Upper graphs data. Lower graphs predicted values. The right graphs show the extrapolation of the percentile power lines toward lower energy factors

rows and inter-row delays ranging from 24 to $120 \mathrm{~ms}$, that correspond from 12 to $61 \mathrm{~ms} / \mathrm{m}$ burden. Schimek et al. (2015) and Ivanova et al. (2015) reported the median size finer for the second and third rows of holes than for the first row, in tests with small-scale benchlike specimens $(210 \mathrm{~mm}$ height, $70 \times 95 \mathrm{~mm}$ burden $\times$ spacing, seven holes per row), where the first row was blasted in virgin material. This is seldom the case in mining or quarrying where, even if only one row is blasted, the burden has usually been damaged by the previous blasts in front of it. Error distributions for blasts with one and several rows have been compared by the Wilcoxon-Mann-Whitney test, and they are not different at a 0.05 significance in the range $40-95 \%$ passing, but they are below $40 \%$ and also at the maximum size. Attempts to incorporate the number of rows into a significant term yielding an improved predictive capability to the model have been unsuccessful. Two major difficulties have been encountered for it: (1) the amount of data for multi-row blasts is significantly smaller than the one row: only 35 blasts out of 169 are multiple row, and, more importantly, (2) there is a significant cross-correlation between the number of rows and the size of the blast in the data used. The results were in all cases a loss of significance (high $p$ value) of some of the parameters of the model, or a marginal gain in the determination coefficient, or both. Be that as it may, the influence of both the 
Table 9 Blast data for sample calculation

\begin{tabular}{ll}
\hline Rock & \\
Discontinuity spacing & $s_{j}=0.5 \mathrm{~m}$ \\
Discontinuity orientation & Dipping toward face, $j_{\mathrm{o}}=0.5$ \\
Uniaxial compressive strength (MPa) & $\sigma_{\mathrm{c}}=100 \mathrm{MPa}$ \\
Elastic modulus & $E=25 \mathrm{GPa}$ \\
P-wave velocity & $c_{P}=4000 \mathrm{~m} / \mathrm{s}$ \\
Geometry & \\
Bench height & $H=10 \mathrm{~m}$ \\
Burden & $B=3.0 \mathrm{~m}$ \\
Spacing & $S=3.2 \mathrm{~m}$ \\
Holes inclination & 0 \\
Stemming length & $l_{\mathrm{S}}=2.5 \mathrm{~m}$ \\
Subdrill length & $l_{J}=1.0 \mathrm{~m}$ \\
Hole diameter & $50-150 \mathrm{~mm}$ \\
Explosive & \\
Explosive energy & $e=3.5 \mathrm{MJ} / \mathrm{kg}$ \\
Explosive density & $\rho_{e}=1200 \mathrm{~kg} / \mathrm{m}^{3}$ \\
In-row delay & $\Delta t=0,10,30 \mathrm{~ms}$ \\
Powder factor, mass & $q=0.21-1.88 \mathrm{~kg} / \mathrm{m}^{3}$ \\
Powder factor, energy & $q e=0.73-6.57 \mathrm{MJ} / \mathrm{m}^{3}$ \\
\hline
\end{tabular}

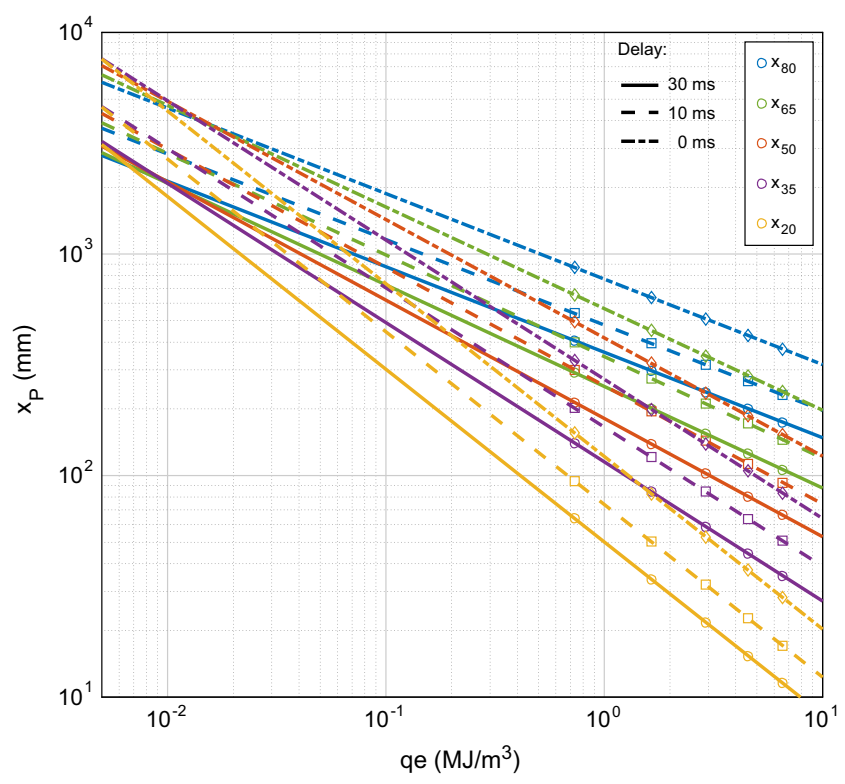

Fig. 14 Sample fragmentation calculation. Left size distributions; right percentiles versus powder factor fan plots. In-row delay 30 ms (solid lines), $10 \mathrm{~ms}$ (dashed lines) and zero (dash-dotted lines)

number of rows and the row-to-row relief time remain a subject of further study.

- Detonator precision The amount of blasts with precise initiation (so considered if the time error is less than $1 \mathrm{~ms}$ ) and non-precise initiation is fairly balanced: 78 precise (seismic, electronic and exploding bridge wire detonators) and 91 non-precise (pyrotechnic, both electric and nonelectric). The error analysis for the two precision categories shows no difference in the error distributions for precise and non-precise initiated blasts in the whole $100-5$ percentile range at a 0.05 significance.

\section{Conclusions}

A model for fragmentation by blasting has been built taking as starting point asteroid collisional fragmentation theory from which non-dimensional functional forms of the 
percentile sizes of the fragments distribution are derived. These functions include a scaling length and two non-dimensional factors: a rock strength-to-energy concentration ratio and a bench shape factor. The model is calibrated with data from 169 blasts for which the blast design variables were reported and the muckpile was sampled and sieved to determine the size distribution. Two additional factors are found to be required: one of them to account for the rock structure-the joints spacing and orientation-and the other for the delay between holes.

The scaling of the percentile sizes has been found to be optimum using the geometric mean of the bench height $H$ and the spacing $S$. The bench shape factor is the ratio of the nominal volume excavated by a blasthole to the scaling length cubed.

The rock strength-to-explosive energy factor is the ratio of the resistance capacity (the strength) of the rock to the driving explosive force; the rock strength is described by the strain energy at rupture per unit volume $\sigma_{\mathrm{c}}^{2} /(2 E), \sigma_{\mathrm{c}}$ being the uniaxial compressive strength and $E$ the Young's modulus. The selection of this parameter has been done on a purely numerical screening of strength variables giving the best determination of the final model. The explosive yield is described as the energy concentration per unit volume, in a direct transpose of the asteroid collision that uses the impactor kinetic energy. Energy concentration is calculated as the powder factor times the explosive energy per unit mass; the explosive energy is rated with the common heat of explosion value.

The rock structure is accounted by a linear form of the joints spacing and the joint orientation descriptions. The joints spacing is written using its non-dimensional ratio to the burden. The joints orientation term is Lilly's number normalized to one.

The influence of the delay is found to be a function of the non-dimensional factor $c_{P} \Delta t / S$; the function decreases as the delay factor increases, reaching a minimum at a certain value of the factor (in the range 30-40 for most percentiles), beyond which the function increases toward an asymptotic value.

The model is applied from 5 to 100 percentile sizes. All the parameters of the model have tight confidence intervals, which indicate a well-conditioned function and a robust model of the existing data with good predictive capability. The expected prediction error is about $20 \%$ across the $100-5$ percentile range.

Acknowledgements The authors are really grateful to Prof. Norbert $\mathrm{H}$ Maerz, Missouri University of Science and Technology at Rolla, MO, for 'excavating' a large number (42) of our fragmentation data sets from early blasting tests with sieving at Rolla and putting them at our disposal. They would also like to thank Prof. Peter Moser, Montanuniversitaet Leoben, for his long-term enthusiastic support of fragmentation by blasting research and his long-standing friendship.
Funding Funding was provided by Universidad Politécnica de Madrid and MONTANUNIVERSITAET LEOBEN.

Open Access This article is distributed under the terms of the Creative Commons Attribution 4.0 International License (http://crea tivecommons.org/licenses/by/4.0/), which permits unrestricted use, distribution, and reproduction in any medium, provided you give appropriate credit to the original author(s) and the source, provide a link to the Creative Commons license, and indicate if changes were made.

\section{References}

Adebola JM, Ajayi OD, Elijah P (2016) Rock fragmentation prediction using Kuz-Ram model. J Environ Earth Sci 6(5):110-115

Ash RL (1973) The influence of geological discontinuities on rock blasting. Ph.D. thesis, University of Minnesota, Minneapolis

Baron LI, Sirotyuk GN (1967) Verification of the applicability of the Rozin-Rammler equation for calculation of the mean diameter of a fragment with the explosive breaking of rock. Explosive Engineering no. 62/19, Izd Nedra, Moscow (in Russian)

Bekkers G (2009) A practical approach to fragmentation optimization at Kidd Mine. In: Sanchidrián JA (ed) Proceedings of 9th international symposium on rock fragmentation by blasting (Fragblast 9), Granada, Spain, 13-17 September 2009. CRC Press/Balkema, Leiden, pp 761-768

Bergmann OR, Wu FC, Edl JW (1974) Model rock blasting measures effect of delays and hole patterns on rock fragmentation. E/MJ Mining Guidebook: Systems for Emerging Technology, June, pp 124-127

Bleakney EE (1984) A study on fragmentation and ground vibration with air space in the blasthole. M.Sc. Thesis, University of Missouri-Rolla

Borquez GV (2006) Drilling, blasting, primary crusher productivitya macro-system view of fragmentation to efficiently recover mineral resources. Proceedings of 8th international symposium on rock fragmentation by blasting (Fragblast 8), Santiago, Chile, 7-11 May 2006. Editec, Santiago, pp 240-245

Boudet J, Ciliberto S, Steinberg V (1996) Dynamics of crack propagation in brittle materials. J Phys II 6(10):1493-1516

Brinkmann JR (1982) The influence of explosive primer location on fragmentation and ground vibrations for bench blasts in dolomitic rock. M.Sc. Thesis, University of Missouri-Rolla

Brunton I, Jankovic A, Kanchibotla S, Licina T, Thornton D, Valery W (2001) Mine to mill optimisation at Porgera gold mine. JKMRC internal report

Cáceres Saavedra J, Katsabanis PD, Pelley CW, Kelebek S (2006) A neural network model for fragmentation by blasting. Proceedings of 8th international symposium on rock fragmentation by blasting (Fragblast 8), Santiago, Chile, 7-11 May 2006. Editec, Santiago, pp 200-206

Chung SH, Katsabanis PD (2000) Fragmentation prediction using improved engineering formulae. Fragblast Int J Blasting Fragm 4(3-4):198-207

Cunningham CVB (1983) The Kuz-Ram model for prediction of fragmentation from blasting. In: Holmberg R, Rustan A (eds) Proceedings of 1st international symposium on rock fragmentation by blasting, Luleå, Sweden, 22-26 August 1983. Luleå Tekniska Universitet, Luleå, pp 439-453

Cunningham CVB (1987) Fragmentation estimations and the KuzRam model-four years on. In: Fourney WL, Dick RD (eds) Proceedings of 2nd international symposium on rock fragmentation by blasting, Keystone, CO, 23-26 August 1987. Society of Experimental Mechanics, Bethel, pp 475-487 
Cunningham CVB (2005) The Kuz-Ram fragmentation model20 years on. In: Proceedings of 3rd world conference on explosives and blasting, Brighton, UK, 13-16 September 2005, pp 201-210

Daehnke A, Rossmanith HP, Knasmillner RE (1996) Blast-induced dynamic fracture propagation. In: Mohanty B (ed) Proceedings of 5th international symposium on rock fragmentation by blasting (Fragblast 5), Montreal, Canada, 25-29 August 1996. Balkema, Rotterdam, pp 13-18

Dick RA, Fletcher LR, D'Andrea DV (1973) A study of fragmentation from bench blasting in limestone at a reduced scale. USBM report of investigation RI 7704, US Bureau of Mines

Djordjevic N (1999) Two-component model of blast fragmentation. In: Proceedings of 6th international symposium on rock fragmentation by blasting (Fragblast 6), Johannesburg, South Africa, 8-12 August 1999. Symposium series S21. SAIMM, Johannesburg, pp 213-219

Dulaney EP, Brace WF (1960) Velocity behavior of a growing crack. J Appl Phys 31:2233-2236

Eissa EA, Kazi A (1988) Relation between static and dynamic Young's moduli for rocks. Int J Rock Mech Min 25:479-482

Engin IC (2009) A practical method of bench blasting design for desired fragmentation based on digital image processing technique and Kuz-Ram model. In: Sanchidrián JA (ed) Proceedings 9th international symposium on rock fragmentation by blasting (Fragblast 9), Granada, Spain, 13-17 September 2009. CRC Press/Balkema, Leiden, pp 257-263

Faramarzi F, Ebrahimi Farsangi MA, Mansouri H (2015) Prediction of rock fragmentation using gamma-based blast fragmentation distribution model. In: Spathis AT et al (eds) Proceedings of 11th international symposium on rock fragmentation by blasting (Fragblast 11), Sydney, Australia, 24-26 August 2015. The Australasian Institute of Mining and Metallurgy, Carlton, pp 685-692

Ford RM (1997) A model for minimizing the cost of rock mass excavation. M.Sc. Thesis, University of Arizona

Fourney WL (2015) The role of stress waves and fracture mechanics in fragmentation. Blasting Fragm 9(2):83-106

Freund LB (1972) Crack propagation in an elastic solid subjected to general loading. J Mech Phys Solids 20:129-152

Gates AO (1915) Kick vs. Rittinger: an experimental investigation in rock crushing performed at Purdue University. Trans AIME 52:875-909

Gaudin AM (1926) An investigation of crushing phenomena. Trans AIME 73:253-316

Gheibie S, Aghababaei H, Hoseinie SH, Pourrahimian Y (2009a) Kuznetsov model's efficiency in estimation of mean fragment size at the Sungun copper mine. In: Sanchidrián JA (ed) Proceedings of 9th international symposium on rock fragmentation by blasting (Fragblast 9), Granada, Spain, 13-17 September 2009. CRC Press/Balkema, Leiden, pp 265-269

Gheibie S, Aghababaei H, Hoseinie SH, Pourrahimian Y (2009b) Modified Kuz-Ram fragmentation model and its use at the Sungun Copper Mine. Int J Rock Mech Min 46(6):967-973

Griffith AA (1921) The phenomena of rupture and flow in solids. Phil Trans R Soc Lond A 221:163-198

Gynnemo M (1997) Investigation of governing factors in bench blasting. Full-scale tests at Kållered and Billingsryd. Publ A84, Chalmers University, Department of Geology, Gothenburg, Sweden (In Swedish)

Hafsaoui A, Talhi K (2009) Influence of joint direction and position of explosive charge on fragmentation. Arab J Sci Eng 34(2A): $125-132$

Hirosaki Y, Murata K, Kato Y, Itoh S (2002) Effect of void size on the detonation pressure of emulsion explosives. In: Furnish MD, Thadhani NN, Horie Y (eds) Shock Compression of condensed matter-2001. American Institute of Physics, College Park, pp 930-933

Hoek E, Brown ET (1980) Underground excavations in rock. Institute of Mining and Metallurgy, London, pp 155-156

Holmberg R (1974) Charge calculations for bench blasting. SveDeFo Report DS 1974:4, Swedish Detonic Research Foundation, Stockholm (In Swedish)

Holsapple KA, Schmidt RM (1987) Point source solutions and coupling parameters in cratering mechanics. J Geophys Res 92(B7):6350-6376

Housen KR, Holsapple KA (1990) On the fragmentation of asteroids and planetary satellites. Icarus 84:226-253

Ivanova R, Ouchterlony F, Moser P (2015) Influence of distorted blasthole patterns on fragmentation as well as roughness of, and blast damage behind, remaining bench face in model-scale blasting. In: Spathis AT et al (eds) Proceedings of 11th international symposium on rock fragmentation by blasting (Fragblast 11), Sydney, Australia, 24-26 August 2015. The Australasian Institute of Mining and Metallurgy, Carlton, pp 693-705

Jaeger JC, Cook NGW (1969) Fundamentals of rock mechanics. Methuen, London, p 184

Jahani M, Taji M (2015) Comparison of empirical fragmentation models at the Gol-Gohar iron ore mine. In: Spathis AT et al (eds) Proceedings of 11th international symposium on rock fragmentation by blasting (Fragblast 11), Sydney, Australia, 24-26 August 2015. The Australasian Institute of Mining and Metallurgy, Carlton, pp 707-713

Johansson D, Ouchterlony F (2013) Shock wave interactions in rock blasting - the use of short delays to improve fragmentation in model-scale. Rock Mech Rock Eng 46(1):1-18

Kanchibotla SS, Valery W, Morrell S (1999) Modelling fines in blast fragmentation and its impact on crushing and grinding. Proceedings of Explo'99-a conference on rock breaking, Kalgoorlie, WA, 7-11 November 1999. The Australasian Institute of Mining and Metallurgy, Carlton, pp 137-144

Katsabanis PD, Liu L (1996) Delay Requirements for fragmentation optimization. In: Franklin JA, Katsabanis T (eds) Measurement of Blast Fragmentation. Balkema, Rotterdam, pp 241-246

Katsabanis PD, Omidi O (2015) The effect of the delay time on fragmentation distribution through small- and medium-scale testing and analysis. In: Spathis AT et al (eds) Proceedings of 11th international symposium on rock fragmentation by blasting (Fragblast 11), Sydney, Australia 24-26 August 2015. The Australasian Institute of Mining and Metallurgy, Carlton, pp 715-720

Katsabanis PD, Tawadrous A, Braun A, Kennedy C (2006) Timing effects on the fragmentation of small blocks of granodiorite. Fragblast Int J Blasting Fragm 10(1-2):83-93

Katsabanis P, Omidi O, Rielo O, Ross P (2014) A review of timing requirements for optimization of fragmentation. Proceedings of 40th annual conference on explosives and blasting technique, Denver, CO, 9-12 February 2014. The International Society of Explosives Engineers, Cleveland, pp 547-558

Kojovic T, Michaux S, McKenzie C (1995) Impact of blast fragmentation on crushing and screening operations in quarrying. Proc Explo'95-a conference exploring the role of breakage in mining and quarrying, Brisbane, Australia, 4-7 September 1995. The Australasian Institute of Mining and Metallurgy, Carlton, pp 427-436

Koshelev EA, Kuznetsov VM, Sofronov ST, Chernikov AG (1971) Statistics of fragments formed when solids are crushed by blasting. Zh Prikl Mekh Tekh Fiz 2:87-100 (in Russian)

Kou S, Rustan A (1993) Computerized design and result predictions of bench blasting. In: Rossmanith HP (ed) Proceedings of 4th international symposium on rock fragmentation by blasting 
(Fragblast 4), Vienna, Austria, 5-8 July 1993. Balkema, Rotterdam, pp 263-271

Kuznetsov VM (1973) The mean diameter of the fragments formed by blasting rock. Soviet Mining Sci 9:144-148

Langefors U, Kihlström B (1963) The modern technique of rock blasting. Almqvist \& Wicksell, Uppsala

Larsson B (1974) Report on blasting of high and low benchesfragmentation from production blasts. In: Proceedings of discussion meeting BK74, Swedish Rock Construction Committee, Stockholm, pp 247-273 (In Swedish)

LeJuge GE, Cox N (1995) The impact of explosive performance on quarry fragmentation. Proc Explo'95-a conference exploring the role of breakage in mining and quarrying, Brisbane, Australia, 4-7 September 1995. The Australasian Institute of Mining and Metallurgy, Carlton, pp 445-452

Lilly PA (1986) An empirical method of assessing rock mass blastability. In: Davidson JR (ed) Proceedings of large open pit mine conference, Newman, WA, October 1986. The Australasian Institute of Mining and Metallurgy, Parkville, pp 89-92

Lilly PA (1992) The use of blastability index in the design of blasts for open pit mines. In: Szwedzicki T, Baird GR, Little TN (eds) Proceedings of Western Australian conference on mining geomechanics, Kalgoorlie, West Australia, 8-9 June 1992. Western Australia School of Mines, Kalgoorlie, pp 421-426

Liu Q (2006) Modification of the Kuz-Ram model for underground hard rock mines. Proceedings of 8th international symposium on rock fragmentation by blasting (Fragblast 8), Santiago, Chile, 7-11 May 2006. Editec, Santiago, pp 185-192

Liu H, Lindqvist PA, Akesson U, Kou SQ, Lindqvist JE (2011) Characterisation of rock properties using texture-based modelling - a geometallurgical approach. In: Proceedings of conference mineral engineering, Luleå, 8-9 Feb 2011, Luleå Tekniska Universitet, Luleå

Lownds CM (1983) Computer modelling of fragmentation from an array of shotholes. In: Holmberg R, Rustan A (eds) Proceedings of 1 st international symposium on rock fragmentation by blasting, Luleå, Sweden, 22-26 August 1983. Luleå Tekniska Universitet, Luleå, pp 455-468

Ma B, Zeng S, Zou D, Guo C (1983) A study of bench blasting in rhyoporphyry at a reduced scale and the statistical analysis of the regularity for fragmentation distribution. In: Holmberg R, Rustan A (eds) Proceedings of 1 st international symposium on rock fragmentation by blasting, Luleå, Sweden, 22-26 August 1983. Luleå Tekniska Universitet, Luleå, pp 857-872

Marchenko LN (1965) Increase of the explosion efficiency in mining of minerals. Nauka, Moscow ((in Russian))

MATLAB Release 2015a (2015) The MathWorks, Inc., Natick

McKenzie CK (2012) Limits blast design: Controlling vibration, gas pressure \& fragmentation. In: Singh PK, Sinha A (eds) Proceedings of 10th international symposium on rock fragmentation by blasting (Fragblast 10), New Delhi, India, 26-29 November 2012. CRC Press/Balkema, Leiden, pp 85-94

Mitrovic SS, Kricak LM, Negovanovic MN, Jankovic IV, Zekovic DI (2009) Influence of rock mass blastability on explosive energy distribution. In: Sanchidrián JA (ed) Proceedings of 9th international symposium on rock fragmentation by blasting (Fragblast 9), Granada, Spain, 13-17 September 2009. CRC Press/ Balkema, Leiden, pp 249-255

Morin MA, Ficarazzo F (2006) Monte Carlo simulation as a tool to predict blasting fragmentation based on the Kuz-Ram model. Comput Geosci 32(3):352-359

Moser P, Grasedieck A, Olsson M, Ouchterlony F (2003) Comparison of the blast fragmentation from lab-scale and full-scale test at Bårarp. In: Holmberg R (ed) Proceedings of EFEE 2nd world conference on explosives and blasting technique, Prague, 10-12 September 2003, pp 449-458
Olsson M, Bergqvist I (2002) Fragmentation in quarries. In: Proceedings of discussion meeting BK 2002. Swedish Rock Construction Committee, Stockholm, pp 33-38 (in Swedish)

Onederra I, Cavanough G, Torrance A (2011) Detonation pressure and temperature measurements of conventional and low-density explosives. Proceedings Explo 2011-blasting-controlled productivity, Melbourne, Australia, 8-9 November 2011. The Australasian Institute of Mining and Metallurgy, Carlton, pp 133-136

Otterness RE, Stagg MS, Rholl SA, Smith NS (1991) Correlation of shot design parameters to fragmentation. Proceedings of 7 th symposium on explosives and blasting research, Las Vegas, Nevada, 6-7 February 1991. Society of Explosives Engineers, Solon, pp 179-190

Ouchterlony F (2005a) The Swebrec $\subseteq$ function, linking fragmentation by blasting and crushing. T I Min Metall A 114:A29-A44

Ouchterlony F (2005b) What does the fragment size distribution of blasted rock look like? In: Holmberg R (ed) Proceedings of EFEE 3rd world conference on explosives and blasting, Brighton, 13-16 September 2005, pp 189-99

Ouchterlony F (2009a) Fragmentation characterization, the Swebrec function and its use in blast engineering. In: Sanchidrián JA (ed) Proceedings of 9th international symposium on rock fragmentation by blasting (Fragblast 9), Granada, Spain, 13-17 September 2009. CRC Press/Balkema, Leiden, pp 3-22

Ouchterlony F (2009b) A common form for fragment size distributions from blasting and a derivation of a generalized Kuznetsov's $\mathrm{x}_{50}$-equation. In: Sanchidrián JA (ed) Proceedings of 9th international symposium on rock fragmentation by blasting (Fragblast 9), Granada, Spain, 13-17 September 2009. CRC Press/Balkema, Leiden, pp 199-208

Ouchterlony F (2016a) The case for the median fragment size as a better fragment size descriptor than the mean. Rock Mech Rock Eng 49(1):143-164

Ouchterlony F (2016b) Reply to discussion of "The case for the median fragment size as a better fragment size descriptor than the mean" by Finn Ouchterlony, Rock Mech Rock Eng, published online 15 March 2015. Rock Mech Rock Eng 49(1):339-342

Ouchterlony F, Moser P (2006) Likenesses and differences in the fragmentation of full-scale and model-scale blasts. Proceedings of 8th international symposium on rock fragmentation by blasting (Fragblast 8), Santiago, Chile, 7-11 May 2006. Editec, Santiago, pp 207-220

Ouchterlony F, Olsson M, Nyberg U, Potts G, Andersson P, Gustavsson L (2005) Optimal fragmentering i krosstäkerFältförsök i Vändletäkten. Report 1:11, MinBas Project, Stockholm (in Swedish)

Ouchterlony F, Olsson M, Nyberg U, Andersson P, Gustavsson L (2006) Constructing the fragment size distribution of a bench blasting round, using the new Swebrec function. Proceedings of 8th international symposium on rock fragmentation by blasting (Fragblast 8), Santiago, Chile, 7-11 May 2006. Editec, Santiago, pp 332-344

Ouchterlony F, Nyberg U, Olsson M, Vikström K, Svedensten P (2010) Optimal fragmentering i krosstäkter, fältförsök i Långåsen. Report 2010:2, MinBas Project 1.2.1: optimal fragmentering vid sprängning II. Swebrec-Swedish Blasting Research Center, Stockholm (in Swedish)

Ouchterlony F, Nyberg U, Olsson M, Widenberg K, Svedensten P (2015) Effects of specific charge and electronic delay detonators on fragmentation in an aggregate quarry, building $\mathrm{KCO}$ design curves. In: Spathis AT et al (eds) Proceedings of 11th international symposium on rock fragmentation by blasting (Fragblast 11), Sydney, Australia, 24-26 August 2015. The Australasian Institute of Mining and Metallurgy, Carlton, pp 727-739 
Ouchterlony F, Sanchidrián JA, Moser P (2016) Percentile fragment size predictions for blasted rock and the fragmentation-energy fan. Rock Mech Rock Eng. doi:10.1007/s00603-016-1094-x

Persson PA, Holmberg R, Lee J (1994) Rock blasting and explosives engineering. CRC Press, Boca Raton, p 11

Price D (1981) Detonation reaction zone length and reaction time. In: Zerilli FJ (ed) Notes on lectures in detonation physics, Report NSWC MP 81-399. Naval Surface Weapons Center, Dahlgren, VA, pp 191-205

Raina AK, Ramulu M, Choudhury PB, Dudhankar A, Chakraborty AK (2002) Fragmentation prediction in different rock masses characterised by drilling index. In: Wang XG (ed) Proceedings of 7 th international symposium on rock fragmentation by blasting (Fragblast 7), Beijing, 11-15 August 2002. Metallurgical Industry Press, Beijing, pp 117-121

Raina AK, Ramulu M, Choudhury PB, Chakraborty AK, Sinha A, Ramesh-Kumar B, Fazal M (2009) Productivity improvement in an opencast coal mine in India using digital image analysis technique. In: Sanchidrián JA (ed) Proceedings of 9th international symposium on rock fragmentation by blasting (Fragblast 9), Granada, Spain, 13-17 September 2009. CRC Press/ Balkema, Leiden, pp 707-716

Roberts DK, Wells AA (1954) The velocity of brittle fracture. Eng Lond 178:820-821

Rodger S, Gricius A (2006) Defining the effect of varying fragmentation on overall mine efficiency. Proceedings of 8th international symposium on rock fragmentation by blasting (Fragblast 8), Santiago, Chile, 7-11 May 2006. Editec, Santiago, pp 313-320

Rollins RR, Wang SW (1990) Fragmentation prediction in bench blasting. Proceedings of 3rd international symposium on rock fragmentation by blasting, Brisbane, Australia, 26-31 August 1990. The Australasian Institute of Mining and Metallurgy, Carlton, pp 195-198

Rosin P, Rammler E (1933) The laws governing the fineness of powdered coal. J Inst Fuel 7:29-36

Rustan A, Nie SL (1987) Fragmentation model at rock blasting. Research report 1987:07. Luleå Tekniska Universitet, Luleå, Sweden

Sanchidrián JA (2015) Ranges of validity of some distribution functions for blast-fragmented rock. In: Spathis AT et al (eds) Proceedings of 11th international symposium on rock fragmentation by blasting (Fragblast 11), Sydney, Australia, 24-26 August. The Australasian Institute of Mining and Metallurgy, Carlton, pp 741-748

Sanchidrián JA, Segarra P, López LM (2006) A practical procedure for the measurement of fragmentation by blasting by image analysis. Rock Mech Rock Eng 39(4):359-382

Sanchidrián JA, Castedo R, López LM, Segarra P, Santos AP (2015) Determination of the JWL constants for ANFO and emulsion explosives from cylinder test data. Central Eur J Energ Mater 12(2):177-194

Schimek P, Ouchterlony F, Moser P (2015) Influence of blasthole delay times on fragmentation as well as characteristics of blast damage behind a remaining bench face through model-scale blasting. In: Spathis AT et al (eds) Proceedings of 11th international symposium on rock fragmentation by blasting (Fragblast 11), Sydney, Australia 24-26 August 2015. The Australasian Institute of Mining and Metallurgy, Carlton, pp 257-265

Scholz CH (1990) The mechanics of earthquakes and faulting. Cambridge University Press, Cambridge, UK, pp 28-29

Schuhmann R (1940) Principles of comminution, I-size distribution and surface calculations. AIME Technical Pub. no. 1189. American Institute of Mining and Metallurgical Engineers, New York, pp 1-11
Scott A (1996) 'Blastability' and blast design. In: Mohanty B (ed) Proceedings of 5th international symposium on rock fragmentation by blasting (Fragblast 5), Montreal, Canada, 25-29 August 1996. Balkema, Rotterdam, pp 27-36

Seber GAF, Wild CJ (2003) Nonlinear regression. Wiley, Hoboken

Segarra P, Sanchidrián JA (2003) The effect of blast design parameters on fragmentation in El Alto quarry (Madrid, Spain). Report 92, Less Fines Project, EC Contract no. G1RD-CT-200000438. Universidad Politécnica de Madrid

Sellers E, Kotze M, Mthalane M (2012) Quantification of the effect of inaccurate drilling on the risk of poor fragmentation and increased blast hazard. In: Singh PK, Sinha A (eds) Proceedings of 10th international symposium on rock fragmentation by blasting (Fragblast 10), New Delhi, India, 26-29 November 2012. CRC Press/Balkema, Leiden, pp 153-161

Singh PK, Roy MP, Drebenstedt C, Prasad B (2015) Blast design parameters and their impact on rock fragmentation. In: Spathis AT et al (eds) Proceedings of 11th international symposium on rock fragmentation by blasting (Fragblast 11), Sydney, Australia, 24-26 August 2015. The Australasian Institute of Mining and Metallurgy, Carlton, pp 755-762

Smith NS (1976) Burden-rock stiffness and its effects on fragmentation in bench blasting. Ph.D. Thesis, University of Missouri-Rolla

Spathis AT (2004) A correction relating to the analysis of the original Kuz-Ram model. Fragblast Int J Blasting Fragm 8(4):201-205

Spathis AT (2009) Formulae and techniques for assessing features of blast-induced fragmentation distributions. In: Sanchidrián JA (ed) Proceedings of 9th international symposium on rock fragmentation by blasting (Fragblast 9), Granada, Spain, 13-17 September 2009. CRC Press/Balkema, Leiden, pp 209-219

Spathis AT (2012) A three parameter rock fragmentation distribution. In: Sanchidrián J, Singh AK (eds) Measurement and analysis of blast fragmentation. CRC Press, Taylor \& Francis Group, London, pp 73-86

Spathis AT (2016) Discussion of "The case for the median fragment size as a better fragment size descriptor than the mean" by Finn Ouchterlony, Rock Mech Rock Eng, 2015. Rock Mech Rock Eng 49(1):335-337

Stagg MS, Nutting MJ (1987) Influence of blast delay time on rock fragmentation: one- tenth-scale tests. US. Bureau of Mines IC 9135, Minneapolis, MN, USA, pp 79-95

Stagg MS, Otterness RE (1995) Screen analysis of full-scale production blasts. Proc $11^{\text {th }}$ Symp on Explosives and Blasting Research, Nashville, TN, 5-9 February 1995. International Society of Explosives Engineers, Cleveland, pp 298-313

Stagg MS, Rholl SA (1987) Effects of accurate delays on fragmentation for single-row blasting in a $6.7 \mathrm{~m}(22-\mathrm{ft})$ bench. In: Fourney WL, Dick RD (eds) Proceedings of 2nd international symposium on rock fragmentation by blasting, Keystone, $\mathrm{CO}$, 23-26 August 1987. Society of Experimental Mechanics, Bethel, pp 210-223

Stagg MS, Rholl SA, Otterness RE (1989) The effect of explosive type and delay between rows on fragmentation. Proceedings of 15th conference on explosives and blasting technique, New Orleans, LA, 5-10 February 1989. Society of Explosives Engineers, Solon, pp 353-366

Strelec S, Gazdek M, Mesec J (2011) Blasting design for obtaining desired fragmentation. Technical Gazette 18(1):79-86

Thornton D, Kanchibotla SS, Brunton I (2001) Modelling the impact of rock mass and blast design variation on blast fragmentation. Proceedings of Explo 2001, Hunter Valley, NSW, 28-31 October 2001. The Australasian Institute of Mining and Metallurgy, Carlton, pp 197-205

Tosun A, Konak G, Toprak T, Karakus D, Onur AH (2014) Development of the Kuz-Ram model to blasting in a limestone quarry. Arch Min Sci 59(2):477-488 
Vanbrabant F, Espinosa Escobar A (2006) Impact of short delays sequence on fragmentation by means of electronic detonators: theoretical concepts and field validation. Proceedings of 8th international symposium on rock fragmentation by blasting (Fragblast 8), Santiago, Chile, 7-11 May 2006. Editec, Santiago, pp 326-331

Weibull W (1939) A statistical theory of the strength of materials. Ingeniörvetenskapsakademiens Handlingar 151:1-45
Weibull W (1951) A statistical distribution function of wide applicability. J Appl Mech Trans ASME 18:293-297

Winzer SR, Anderson DA, Ritter AP (1983) Rock fragmentation by explosives. In: Holmberg R, Rustan A (eds) Proceedings of 1st international symposium on rock fragmentation by blasting, Luleå, Sweden, August 23-26. Luleå Tekniska Universitet, Luleå, pp 225-249 